\title{
Antiproliferation and cell apoptosis inducing bioactivities of constituents from Dysosma versipellis in PC3 and Bcap-37 cell lines
}

\author{
Xiaogiang Xu, Xiuhong Gao, Linhong Jin, Pinaki S Bhadury, Kai Yuan, Deyu Hu, Baoan Song ${ }^{*}$ and Song Yang*
}

\begin{abstract}
Background: Recently, interest in phytochemicals from traditional Chinese medicinal herbs with the capability to inhibit cancer cells growth and proliferation has been growing rapidly due to their nontoxic nature. Dysosma versipellis as Bereridaceae plants is an endemic species in China, which has been proved to be an important Chinese herbal medicine because of its biological activity. However, systematic and comprehensive studies on the phytochemicals from Dysosma versipellis and their bioactivity are limited.

Results: Fifteen compounds were isolated and characterized from the roots of Dysosma versipellis, among which six compounds were isolated from this plant for the first time. The inhibitory activities of these compounds were investigated on tumor cells PC3, Bcap-37 and BGC-823 in vitro by MTT method, and the results showed that podophyllotoxone (PTO) and 4'-demethyldeoxypodophyllotoxin (DDPT) had potent inhibitory activities against the growth of human carcinoma cell lines. Subsequent fluorescence staining and flow cytometry analysis indicated that these two compounds could induce apoptosis in PC3 and Bcap-37 cells, and the apoptosis ratios reached the peak $(12.0 \%$ and $14.1 \%)$ after $72 \mathrm{~h}$ of treatment at $20 \mu \mathrm{M}$, respectively.
\end{abstract}

Conclusions: This study suggests that most of the compounds from the roots of $D$. versipellis could inhibit the growth of human carcinoma cells. In addition, PTO and DDPT could induce apoptosis of tumor cells.

\section{Background}

Cancer is the major cause of human deaths worldwide because of its high incidence and mortality. Thousands of people die of cancer each year despite aggressive treatment regimens that include surgery, chemotherapy and radiotherapy. Due to the infiltrative nature and the rapid recurrence of the malignant tumor, complete surgical resection of these tumors is typically not achieved $[1,2]$, and the conventional radiation and chemotherapy are often intolerable due to the strong systemic toxicity and local irritation [3-5]. These factors highlight the urgent need for new therapies or therapeutic combinations to improve the survival and quality of life of cancer patients.

\footnotetext{
* Correspondence: songbaoan22@yahoo.com; fcc.syang@gzu.edu.cn State Key Laboratory Breeding Base of Green Pesticide and Agricultural Bioengineering, Key Laboratory of Green Pesticide and Agricultural Bioengineering, Ministry of Education, Guizhou University, Guiyang 550025,
} China

(c) 2011 Xu et al; licensee BioMed Central Ltd. This is an Open Access article distributed under the terms of the Creative Commons Attribution License (http://creativecommons.org/licenses/by/2.0), which permits unrestricted use, distribution, and reproduction in any medium, provided the original work is properly cited.
In recent years, interest in phytochemicals from traditional Chinese medicinal herbs has been growing rapidly due to their ability to inhibit the growth and proliferation of cancer cells [6-9]. Due to their nontoxic nature, they are often employed in medical applications. Among of them, flavonoids and lignans present in traditional Chinese medicines have been revealed having significant activities against some forms of cancer $[1,10]$. The lignan podophyllotoxin is a plant toxin that exerts its cytotoxicity effect by inhibiting microtubule assembly and promoting cells to die via apoptosis [11]. However, it is not used as a clinical therapeutic agent due to its serious side effects. Extensive structure modifications were performed to obtain more potent and less toxic antitumor agents, e.g. etoposide [12] and teniposide [13] are currently used in anticancer therapy. Besides, some researchers found that podophyllotoxin and its derivatives had inhibitory effect on PC3 and other cells [14-16]. One of the popular Chinese herbal medicines, Dysosma versipellis (Hance) M. Cheng which belongs to

\section{Biomed Central}


Berberidaceae in Dysosma Family and is used as a source of podophyllotoxin [16] is a perennial herbaceous species grown in the understory of mixed evergreen and deciduous forests of China. In some folk remedies, $D$. versipellis (Hance) $M$. Cheng has been widely used to clear sputum, kill parasites and treat epidemic encephalitis B and epidemic parotitis. Previous studies have indicated that constituents and extracts of this traditional Chinese medicinal plant have growth inhibitory activities against various tumors in vivo or in vitro [16-18]. However, systematic and comprehensive studies have not been performed with regard to the chemical constituents from $D$. Versipellis and apoptosis-inducing effect of these components.

Dysosma versipellis, an endangered and endemic Bereridaceae plant species of China, has been proved to be an important Chinese herbal medicine because of its biological activity. In this study, fifteen compounds were isolated from the rhizomes of $D$. versipellis which was grown in Guizhou and identified by spectroscopic analysis and physicochemical data as $\beta$-sitosterol (1), 4'demethylpodophyllotoxin (2), kaempferol (3), picropodophyllotoxin-4-O-glucoside (4), cleistanthin-B (5), kaempferol-3-O- $\beta$ - $D$-glucopyranoside (6), 4'-demethylpodophyllotoxin-4-O-glucoside (7), quercetin3-O- $\beta$ - $D$ glucopyranoside (8), icropodophyllotoxin-4-O- $\beta$ - $D$-glucopyranosyl-( $1 \rightarrow 6)-\beta-D$-glucopyranoside $(9)$, quercetin (10), daucosterol (11), podophyllotoxone (PTO, 12), vanillic acid (13), 4'-demethyldeoxypodophyllotoxin (DDPT, 14), and sucrose (15). Among them, (5), (7), (8), (12), (13) and (15) were obtained from the plants for the first time. All the compounds were then bioassayed on human prostatic carcinoma cell line PC3, human breast cancer cell line Bcap-37, human gastric carcinoma cell line BGC-823 and mouse embryonic fibroblast cell line NIH3T3 in vitro by MTT method. It was found that DDPT had the most potent inhibitory activities against the growth of human carcinoma cell lines than other compounds extracted from $D$. versipellis. And PTO obtained from the plants for the first time also had high antitumor activity. There are a few reports on the anticancer effects of PTO and DDPT on various tumor cells recently [19-21]. And it was found that the inhibitory rate of PTO $(100 \mu \mathrm{g} / \mathrm{mL})$ on P388 murine leukemia cell proliferation was $99.0 \%$. Also PTO could induce HL-60 human leukemia cells apoptosis, which might be related with down-regulation of Bcl-2 expression. Other studies have found that DDPT possessed antitumor activity on A549 human lung carcinoma cell and SK-MEL-2 human melanoma cell with $\mathrm{EC}_{50}$ of $0.023 \mu \mathrm{g} / \mathrm{mL}$ and $0.015 \mu \mathrm{g} / \mathrm{mL}$ respectively. However, no report was found on the anticancer activities of PTO and DDPT on PC3, Bcap-37 and BGC-823 cells. This prompted us to study the anticancer activities of PTO and DDPT separated from the rhizomes of D. versipellis grown in Guizhou on the three kinds of cells mentioned above and investigate their preliminarily mechanism of action as potent anticancer agents. Thus, further investigations of PTO and DDPT on the three cells lines were carried out on PC3, Bcap-37, and BGC-823 cells. The $\mathrm{IC}_{50}$ of PTO and DDPT on the three cell lines were determined. Furthermore, experimental results of fluorescent staining and flow cytometry analysis indicated that PTO and DDPT could induce apoptosis in PC3 and Bcap-37 cells, with the apoptosis ratios of PC3 cells were $12.0 \%$ and $14.1 \%$ after $72 \mathrm{~h}$ of treatment at $20 \mu \mathrm{M}$, respectively. To the best of our knowledge, this is the first report on apoptosis inducing and antitumor activity of PTO and DDPT on PC3, Bcap-37, and BGC-823 cells.

\section{Methods}

Analysis and Instruments

${ }^{1} \mathrm{H}$ NMR, ${ }^{13} \mathrm{C}$ NMR, and DEPT spectra were measured on a JOEL-ECX $500 \mathrm{MHz}$ NMR spectrometer in $\mathrm{CDCl}_{3}, \mathrm{CD}_{3} \mathrm{OD}$, or DMSO- $d_{6}$ using tetramethylsilane (TMS) as an internal standard. The IR spectra were obtained in the $\mathrm{KBr}$ pellet using a SHIMADZU-IR Prestige-21 spectrometer. Melting points were determined on an XT-4 digital microscope (Beijing Tech Instrument Co.) Analytical TLC was performed on silica gel GF254 (400 mesh), and column chromatographic operations were performed on Silica gel (100200 or 200-300 mesh, Qingdao Haiyang Chemical Co.). In addition, Sephadex LH-20 column chromatographic instrument (Beijing Huideyi Tech Instrument Co.) was employed for the extraction and purification of chemical composition.

\section{Plant material}

The rootstalk of D. versipellis was collected in Qingzhen, Guizhou Province, China, in the month of May 2008. The voucher specimen was identified as D. versipellis (hance.) M.Cheng by Qing-De Long, the Dean of teaching-research section, School of Pharmacy of Guiyang Medical University, and was submitted to our laboratory for further investigation.

\section{Extraction and isolation}

The dried roots of $D$. versipellis $(20 \mathrm{~kg}$ ) from Guizhou Province were powdered and extracted by maceration in $80 \%$ industrial alcohol $(50 \mathrm{~L}$, each $4 \mathrm{~d})$ for three times. The extracts which filtered and washed with alcohol each time were combined and reduced in vacuo to afford $4 \mathrm{~kg}$ crude extract. A part of crude extract $(950$ g) was further extracted with petroleum ether, chloroform and ethyl acetate to obtain three fractions of $40 \mathrm{~g}$, $2 \mathrm{~kg}$ and $280 \mathrm{~g}$ respectively. 
The petroleum ether extract (40 g) was chromatographed on silica gel column (200-300 mesh) and eluted with a PE-EtOAc (20:1 0:1) gradient, and recrystallized with methanol to give compound $\mathbf{1}(300 \mathrm{mg})$.

The chloroform extract (100 g) chromatographed on silica gel column (100-200 mesh) was eluted with $\mathrm{CHCl}_{3}-\mathrm{MeOH}(1: 0 \sim 0: 1)$ and PE-EtOAc (20:1 0:1) to obtain fractions 1-5, respectively. Compounds 2 (100 $\mathrm{mg})$ and $3(200 \mathrm{mg})$ was obtained by PTLC and eluting with $\mathrm{CHCl}_{3}-\mathrm{MeOH}$ (6:1 and 5:1) from fractions 1 and 2, respectively. The fraction 3 was evaluated by Sephadex LH-20 and eluted with acetone to afford compounds 4 $(15 \mathrm{mg})$ and $5(10 \mathrm{mg})$. And fraction 4 was eluted with PE-EtOAc (10:1) and recrystallized with acetone to give compound $12(20 \mathrm{mg})$. The filtrate from fraction 5 was eluted with PE-EtOAc (9:1 and 10:1, respectively) to afford compounds $13(25 \mathrm{mg})$ and $14(23 \mathrm{mg})$.

The ethyl acetate extract (55 g) was chromatographed on silica gel column (100-200 mesh) and eluted with $\mathrm{CHCl}_{3}-\mathrm{MeOH}$ (15:1 0:1) to obtain fractions 1-3. The fraction 1 was evaluated by Sephadex LH-20 (methanol) to give compound $10(50 \mathrm{mg})$. Compounds 6 (140 mg) and 7 (209 $\mathrm{mg}$ ) were obtained by silica gel column chromatography (200-300 mesh) and eluting with $\mathrm{CHCl}_{3}$ $\mathrm{MeOH}(8: 1)$ from fraction 2. The fraction 3 was further chromatographed on silica gel column (100-200 mesh) and eluted with $\mathrm{CHCl}_{3}-\mathrm{MeOH}(10: 1 \sim 0: 1)$ to give subfractions 1-3. Compound 8 (30 mg) were obtained by Sephadex LH-20 (methanol) from subfraction 1. The subfraction 2 was recrystallized with $\mathrm{CHCl}_{3}-\mathrm{MeOH}(8: 1)$ to afford compound $15(15 \mathrm{mg})$. The subfraction 3 was recrystallized with $\mathrm{MeOH}$ and $\mathrm{CHCl}_{3}-\mathrm{MeOH}(9: 1)$ to give compound 9 (19 $\mathrm{mg}$ ) and compound $11(18 \mathrm{mg})$, respectively.

\section{Anticancer activity bioassay Cell culture}

Human prostate cancer cell line PC3, breast cancer cell line Bcap-37, and gastric cancer cell line BGC-823 were purchased from Institute of Biochemistry and Cell Biology, China Academy of Science and cultured in RPMI 1640 medium supplemented with $10 \%$ heat-inactivated fetal bovine serum (FBS). Mouse embryonic fibroblast cell line NIH 3T3 was also obtained from the same place and cultured in DMEM supplemented with $10 \%$ FBS. All cell lines were maintained at $37^{\circ} \mathrm{C}$ in a humidified 5\% carbon dioxide and 95\% air incubator.

\section{MTT asssy}

All tested compounds were dissolved in DMSO (1-100 $\mu \mathrm{M}$ solution) and subsequently diluted in the culture medium before treatment of the cultured cells. Tested cells were plated in 96-well plates at a density $2 \times 10^{3}$ cells/well/100 $\mu \mathrm{L}$ of the proper culture medium and treated with the compounds at 1 to $100 \mu \mathrm{M}$ for $72 \mathrm{~h}$. In parallel, the cells treated with $0.1 \%$ DMSO served as control. An MTT assay (Roche Molecular Biochemicals, 1465-007) was performed $30 \mathrm{~h}$ later according to the instructions provided by Roche. This assay was based on the cellular cleavage of MTT into formazane which is soluble in cell culture medium. Any absorbance caused by formazan was measured at $595 \mathrm{~nm}$ with a microplate reader (BIO-RAD, model 680), which is directly proportional to the number of living cells in culture. The experiment was performed in triplicate. The percentage cytotoxicity was calculated using the formula.

$$
\% \text { Cytotoxicity }=\frac{(\text { Control abs }- \text { Blank abs })-(\text { Test abs }- \text { Blank abs })}{(\text { Control abs }- \text { Blank abs })} \times 100
$$

\section{AO/EB staining}

Cells were seeded at a concentration of $5 \times 10^{4} \mathrm{cell} / \mathrm{ml}$ in a volume of $0.6 \mathrm{~mL}$ on sterile cover slip in 6-well tissue culture plates. Following incubation, the medium was removed and replaced with fresh medium plus 10\% FBS and supplemented with podophyllotoxone and 4'demethyldeoxypodophyllotoxin $(20 \mu \mathrm{M})$. After the treatment period, the cover slip with monolayer cells was inverted on the glass slide with $20 \mu \mathrm{L}$ of $\mathrm{AO} / \mathrm{EB}$ stain $(100 \mu \mathrm{g} / \mathrm{mL})$. The fluorescence was read on an IX71SIF3 fluorescence microscope (OLYPUS Co., Japan).

\section{Hoechst 33258 staining}

Cells grown on sterile cover slip in 6-well tissue culture plates were treated with podophyllotoxone and 4'demethyldeoxypodophyllotoxin $(20 \mu \mathrm{M})$ for a certain range of treatment time. The culture medium containing compounds was removed and the cells were fixed in 4\% paraformaldehyde for $10 \mathrm{~min}$. After washing twice with PBS, cells were stained with $0.5 \mathrm{~mL}$ of Hoechst 33258 staining (Beyotime) for $5 \mathrm{~min}$. After washing twice with PBS, stained nuclei were observed under an IX71SIF-3 fluorescence microscope by using $350 \mathrm{~nm}$ excitation and $460 \mathrm{~nm}$ emission.

\section{TUNEL assays}

TdT-UTP nick end labeling (TUNEL) assays were performed with colorimetric TUNEL apoptosis assay kit according to the manufacturer's instructions (Beyotime). Cells grown in 6 well culture clusters were treated as mentioned in mitochondrial depolarization assay. In short, Bcap-37 cells grown in 6-well tissue culture plates were washed with PBS and fixed in $4 \%$ paraformaldehyde for $40 \mathrm{~min}$. After washing once with PBS, cells were permeabilized with immunol staining wash buffer (Beyotime) for $2 \mathrm{~min}$ on ice. Cells were washed once with $\mathrm{PBS}$ again and incubated in $0.3 \% \mathrm{H}_{2} \mathrm{O}_{2}$ in methanol at room temperature for $20 \mathrm{~min}$ to inactivate the endogenous peroxidases after which the cells were washed for three times with PBS. Thereafter, the cells were incubated with $2 \mu \mathrm{L}$ of TdT-enzymea and $48 \mu \mathrm{L}$ of 
Biotin-dUTP per specimen for $60 \mathrm{~min}$ at $37^{\circ} \mathrm{C}$. After termination for $10 \mathrm{~min}$, cells were incubated with streptavidin-HRP (50 $\mu \mathrm{L}$ per specimen) conjugate diluted at 1:50 in diluent of streptavidin-HRP for $30 \mathrm{~min}$. After washing three times with PBS, cells were incubated with diaminobenzidine (DAB) solution (200 $\mu \mathrm{L}$ per specimen) for $10 \mathrm{~min}$. This was again followed by washing with PBS for two times and the result was imaged under an XDS-1B inverted biological microscope (Chongqing photoelectric device CO.).

\section{Flow cytometry analysis}

Prepared PC3 cells $\left(1 \times 10^{6} / \mathrm{mL}\right)$ were washed twice with cold PBS and then re-suspended gently in $500 \mu \mathrm{L}$ binding buffer. Thereafter, cells were stained in $5 \mu \mathrm{L}$ Annexin V-FITC and shaked well. Finally, $5 \mu \mathrm{L}$ PI was added to these cells and incubated for $20 \mathrm{~min}$ in a dark place, analyzed by FACS Calibur, Becton Dickinson.

\section{Statistical analysis}

All statistical analyses were performed with SPSS 10.0. Data were analyzed by one-way analysis of variance (ANOVA). Mean separations were performed using the least significant difference method (LSD test). Each experiment had three replicates and all experiments were run three times with similar results. Measurements from all the replicates were combined and treatment effects analyzed.

\section{Results and Discussion Chemistry}

The root of D. versipellis collected from Guizhou province was studied and fifteen compounds were isolated from the ethanol extracts, which were identified based on their physicochemical as well as spectroscopic data as $\beta$-sitosterol (1), 4'-demethylpodophyllotoxin (2), kaempferol (3), picropodophyllotoxin-4-O-glucoside (4), cleistanthin-B (5), kaempferol-3-O- $\beta$ - $D$-glucopyranoside (6), 4'-demethylpodo-phyllotoxin-4-O-glucoside (7), quercetin-3-O- $\beta$ - $D$-glucopyranoside (8), icropodo- phyllotoxin-4- $O-\beta$ - $D$-glucopyranosyl- $(1 \rightarrow 6)-\beta$ - $D$-glucopyranoside (9), quercetin (10), daucosterol (11), podophyllotoxone (12), vanillic acid (13), 4'-demethyldeoxypodo-phyllotoxin (14), sucrose (15), as shown in Figure 1. It can be seen that these compounds can be classified as two steroids (compounds $\mathbf{1}$ and 11), four flavonoids (compounds $3, \mathbf{6}, \mathbf{8}$ and 10), seven lignans (compounds 2, 4, 5, 7, 9, 12 and 14), an organic acid (compound 13), and sucrose (15).

Compound 1, white acerate crystal; m.p. $136 \sim 137^{\circ} \mathrm{C}$; molecular formula: $\mathrm{C}_{29} \mathrm{H}_{50} \mathrm{O} ;{ }^{1} \mathrm{H}$ NMR $\left(\mathrm{CDCl}_{3}, 500\right.$ $\mathrm{MHz}) \delta: 5.35(1 \mathrm{H}, \mathrm{d}, J=2.6 \mathrm{~Hz}, \mathrm{H}-6), 3.50 \sim 3.46(1 \mathrm{H}$, $\mathrm{m}, \mathrm{H}-3$ ), $0.68 \sim 2.29$ (continuous peaks); ${ }^{13} \mathrm{C}$ NMR $\left(\mathrm{CDCl}_{3}, 125 \mathrm{MHz}\right) \delta: 140.8$ (C-5), 121.8 (C-6), 71.9 (C3), 56.8 (C-14), 56.1 (C-17), 50.2 (C-9), 45.9 (C-4), 42.4 (C-13), 39.9 (C-12), 37.3 (C-1), 36.5 (C-10), 36.2 (C-20),
32.0 (C-22), 34.0 (C-7), 32.0 (C-8), 31.8 (C-2), 29.2 (C24), 28.3 (C-25), 28.2 (C-16), 26.2 (C-28), 24.4 (C-15), 23.2 (C-27), 21.2 (C-11), 19.9 (C-26), 19.5 (C-19), 19.1 (C-23), 18.9 (C-21), 12.1 (C-29), 11.9 (C-18). As analyzed above, it was identified as $\beta$-sitosterol [22].

Compound 2, colorless crystal; m.p. $234 \sim 237^{\circ} \mathrm{C}$; molecular formula: $\mathrm{C}_{21} \mathrm{H}_{20} \mathrm{O}_{8} ;{ }^{1} \mathrm{H}$ NMR $\left(\mathrm{CD}_{3} \mathrm{OD}, 500\right.$ MHz) $\delta: 7.18(1 \mathrm{H}, \mathrm{s}, \mathrm{H}-5), 6.49(1 \mathrm{H}, \mathrm{s}, \mathrm{H}-8), 6.43(2 \mathrm{H}$, s, H-2', H-6'), 5.97 ( $2 \mathrm{H}, \mathrm{dd}, J=0.9 \mathrm{~Hz}, J=1.0 \mathrm{~Hz}$, $\left.\mathrm{OCH}_{2} \mathrm{O}\right), 4.78(1 \mathrm{H}, \mathrm{d}, J=4.8 \mathrm{~Hz}, \mathrm{H}-4), 4.52 \sim 4.40$ $(2 \mathrm{H}, \mathrm{m}, \mathrm{H}-1, \mathrm{H}-3 \mathrm{a} \alpha), 4.12(1 \mathrm{H}, \mathrm{t}, J=9.6 \mathrm{~Hz}, \mathrm{H}-3 \mathrm{a} \beta)$, $3.70\left(6 \mathrm{H}, \mathrm{s}, 3^{\prime}, 5^{\prime}-\mathrm{OCH}_{3}\right), 3.02(1 \mathrm{H}, \mathrm{dd}, J=9.5 \mathrm{~Hz}, J$ $=2.5 \mathrm{~Hz}, \mathrm{H}-2), 2.84(1 \mathrm{H}, \mathrm{m}, \mathrm{H}-3) ;{ }^{13} \mathrm{C} \mathrm{NMR}\left(\mathrm{CD}_{3} \mathrm{OD}\right.$, $125 \mathrm{MHz}) \delta$ : 174.4 (C-2a), 147.3 (C-3'), 147.3 (C-5'), 147.0 (C-6 ), 147.0 (C-7), 135.2 (C-1'), 135.0 (C-4), 131.7 (C-9), 131.3 (C-10), 109.3 (C-8), 109.1 (C-6), 109.1 (C-2'), 106.5 (C-5), $101.3\left(\mathrm{OCH}_{2} \mathrm{O}\right), 71.8(\mathrm{C}-3 \mathrm{a})$, 71.0 (C-4), 55.9 (3', 5'-OMe), 44.8 (C-2), 44.0 (C-1), 40.7 (C-3). As analyzed above, it was identified as 4'demethyl- podophyllotoxin [23].

Compound 3, yellow powder; m.p. $281 \sim 283^{\circ} \mathrm{C}$; molecular formula: $\mathrm{C}_{15} \mathrm{H}_{10} \mathrm{O}_{6} ;{ }^{1} \mathrm{H}$ NMR $\left(\mathrm{CD}_{3} \mathrm{OD}, 500 \mathrm{MHz}\right)$ $\delta: 12.05(1 \mathrm{H}, \mathrm{s}, 5-\mathrm{OH}), 8.03(2 \mathrm{H}, \mathrm{d}, J=9.2 \mathrm{~Hz}, \mathrm{H}-2, \mathrm{H}-$ 6' $), 6.90\left(2 \mathrm{H}, \mathrm{d}, J=9.2 \mathrm{~Hz}, \mathrm{H}-3^{\prime}, 5^{\prime}\right), 6.40(1 \mathrm{H}, \mathrm{d}, J=$ $1.8 \mathrm{~Hz}, \mathrm{H}-8), 6.14(1 \mathrm{H}, \mathrm{d}, J=2.3 \mathrm{~Hz}, \mathrm{H}-6) ;{ }^{13} \mathrm{C}$ NMR $\left(\mathrm{CD}_{3} \mathrm{OD}, 125 \mathrm{MHz}\right) \delta: 175.8$ (C-4), 164.1 (C-7), 161.3 (C-5), 159.3 (C-4'), 157.0 (C-9), 146.2 (C-2), 135.8 (C-3), 129.6 (C-6'), 129.6 (C-2'), 122.5 (C-1'), 115.5 (C-3'), 115.4 (C-5), 103.3 (C-10), 98.3 (C-6), 93.7 (C-8). As analyzed above, it was identified as kaempferol [24].

Compound 4, white acerate crystal; m.p. $228 \sim 230^{\circ} \mathrm{C}$; molecular formula: $\mathrm{C}_{28} \mathrm{H}_{32} \mathrm{O}_{13} ;{ }^{1} \mathrm{H}$ NMR (DMSO- $d_{6}$, $500 \mathrm{MHz}) \delta: 7.29$ (1H, s, H-5), 6.58 (2H, s, H-2', H-6'), $6.09(1 \mathrm{H}, \mathrm{s}, \mathrm{H}-8), 5.92\left(2 \mathrm{H}, \mathrm{d}, J=5.2 \mathrm{~Hz}, \mathrm{OCH}_{2} \mathrm{O}\right), 4.68$ $(1 \mathrm{H}, \mathrm{d}, J=8.6 \mathrm{~Hz}, \mathrm{H}-4), 4.62(1 \mathrm{H}, \mathrm{d}, J=8.6 \mathrm{~Hz}, \mathrm{H}-$ $3 \mathrm{a} \alpha), 4.48(1 \mathrm{H}, \mathrm{d}, J=4.0 \mathrm{~Hz}, \mathrm{H}-3 \mathrm{a} \beta), 3.97(1 \mathrm{H}, \mathrm{d}, J=$ $6.9 \mathrm{~Hz}, \mathrm{H}-1), 3.73$ (6H, s, 3'-OMe, 5'-OMe), 3.66 (3H, s, 4'-OMe), $3.60(1 \mathrm{H}, \mathrm{d}, J=3.2 \mathrm{~Hz}, \mathrm{H}-2), 2.84 \sim 2.66(1 \mathrm{H}$, m, H-3), Glc: $5.06(1 \mathrm{H}, \mathrm{d}, J=7.5 \mathrm{~Hz}, \mathrm{H}-1 "), 4.46(1 \mathrm{H}, \mathrm{d}$, $J=4.6 \mathrm{~Hz}, \mathrm{H}-3$ "), $4.40(1 \mathrm{H}, \mathrm{dd}, J=6.8 \mathrm{~Hz}, J=3.5 \mathrm{~Hz}$, H-6"), 3.09 3.21 (4H, m, H-2", H-4" H-6"); ${ }^{13} \mathrm{C}$ NMR (DMSO- $\left.d_{6}, 125 \mathrm{MHz}\right) \delta: 178.2$ (C-2a), 153.3 (C-3', 5'), 146.7 (C-6), 146.2 (C-7), 138.7(C-1'), 136.5 (C-4'), 132.1 (C-9), 132.0 (C-10), 107.8 (C-5), 107.6 (C-8), 106.6 (C-2', 6'), $101.2\left(\mathrm{OCH}_{2} \mathrm{O}\right), 77.5(\mathrm{C}-4), 70.2(\mathrm{C}-11), 60.5$ (4'$\left.\mathrm{OCH}_{3}\right), 56.3\left(3^{\prime}, 5^{\prime}-\mathrm{OCH}_{3}\right), 43.9(\mathrm{C}-1), 44.1(\mathrm{C}-2), 41.9$ (C-3), Glc: 104.1 (C-1"), 74.3 (C-2”), 77.3 (C-3", 5”), 70.04 (C-4"), 61.6 (C-6"). As analyzed above, it was identified as picropodophyllotoxin-4-O-glucoside [25].

Compound 5, white powder; m.p. $154 \sim 156^{\circ} \mathrm{C}$; molecular formula: $\mathrm{C}_{27} \mathrm{H}_{26} \mathrm{O}_{12} ;{ }^{1} \mathrm{H} \mathrm{NMR}\left(\mathrm{CD}_{3} \mathrm{OCD}_{3}, 500 \mathrm{MHz}\right)$ $\delta: 8.28(1 \mathrm{H}, \mathrm{s}, \mathrm{H}-5), 7.11\left(1 \mathrm{H}, \mathrm{d}, J=1.7 \mathrm{~Hz}, \mathrm{H}-5^{\prime}\right), 6.98$ $(1 \mathrm{H}, \mathrm{dd}, J=5.2 \mathrm{~Hz}, J=2.3 \mathrm{~Hz}, \mathrm{H}-8), 6.90(1 \mathrm{H}, \mathrm{d}, J=$ $\left.1.8 \mathrm{~Hz}, \mathrm{H}-2^{\prime}\right), 6.88\left(1 \mathrm{H}, \mathrm{dd}, J=7.5 \mathrm{~Hz}, J=2.3 \mathrm{~Hz}, \mathrm{H}-6^{\prime}\right)$, 

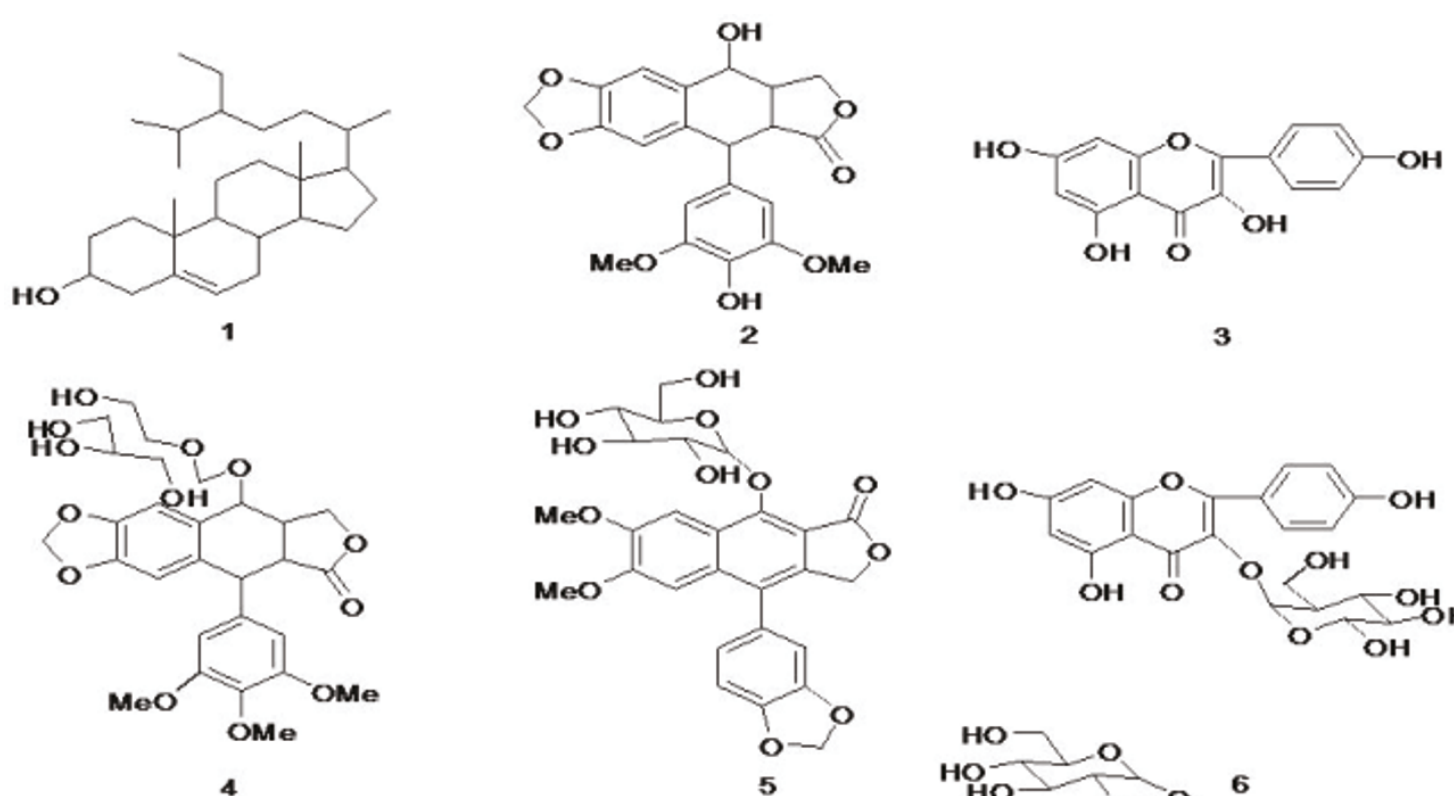

3

4<smiles></smiles><smiles>O=c1c(OC2OC(O)C(O)C(O)C(O)C(O)C2O)c(-c2ccc(O)c(O)c2)oc2cc(O)cc(O)c12</smiles><smiles>O=c1c(OC2OC(O)C(O)C(O)C(O)C2O)c(-c2ccc(O)cc2)oc2cc(O)cc(O)c12</smiles>

8

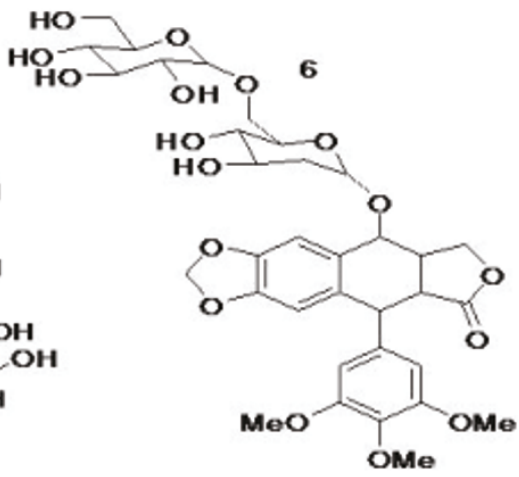<smiles>O=c1c(O)c(-c2ccc(O)c(O)c2)oc2cc(O)cc(O)c12</smiles>

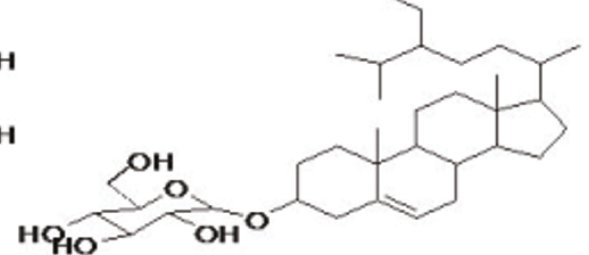<smiles>COc1cc(C2c3cc4c(cc3C(=O)C3COC(=O)C32)OCO4)cc(OC)c1OC</smiles>

10

11<smiles>COc1ccc(C(=O)O)cc1O</smiles><smiles>COc1cc(C2c3cc4c(cc3CC3COC(=O)C32)OCO4)cc(OC)c1O</smiles>

14<smiles>OC[C@H]1O[C@H](O[C@]2(CO)O[C@H](CO)[C@@H](O)[C@H](O)[C@H]2O)[C@H](O)[C@@H](O)[C@@H]1O</smiles>

13

15

Figure 1 The structures of compounds 1-15. These compounds were obtained from the root of Dysosma versipellis and identified by spectroscopic analysis and physicochemical data. 
$6.10\left(2 \mathrm{H}, \mathrm{s}, 3\right.$ ', $\left.4^{\prime}-\mathrm{OCH}_{2} \mathrm{O}\right), 5.60(2 \mathrm{H}, \mathrm{dd}, J=21.0 \mathrm{~Hz}, J$ $=2.3 \mathrm{~Hz}, \mathrm{H}-3 \mathrm{a}), 4.94(1 \mathrm{H}, \mathrm{d}, J=8 \mathrm{~Hz}, \mathrm{H}-1 "), 4.00(3 \mathrm{H}$, s, 6-OMe), $3.96(1 \mathrm{H}, \mathrm{d}, J=6.3 \mathrm{~Hz}, \mathrm{H}-6$ "), $3.74(3 \mathrm{H}, \mathrm{s}, 7-$ OMe), 3.69 (1H, d, $J=4 \mathrm{~Hz}, \mathrm{H}-6$ "), $3.51 \sim 3.49$ (4H, m, $\mathrm{H}-2$ " $\sim \mathrm{H}-5$ "); ${ }^{13} \mathrm{C}$ NM R $\left(\mathrm{CD}_{3} \mathrm{OCD}_{3}, 125 \mathrm{MHz}\right) \delta$ : 136.5 (C-1), 120.2 (C-2), 128.2 (C-3), 146.2 (C-4), 102.2 (C-5), 153.0 (C-6), 151.5 (C-7), 106.7 (C-8), 131.6 (C-9), 131.3 (C-10), 129.8 (C-1'), 111.7 (C-2'), 148.3 (C-3'), 148.4 (C4'), 108.7 (C-5'), 124.6 (C-6'), 169.9 (C-2a), 68.1 (C-3a), 56.4 (6-OMe), 55.7 (7-OMe), $102.7\left(\mathrm{OCH}_{2} \mathrm{O}\right), 106.3(\mathrm{C}-$ 1"), 73.4 (C-2"), 75.2 (C-3"), 71.4 (C-4"), 78.1 (C-5"), $62.8\left(\mathrm{C}-6^{\prime \prime}\right)$. As analyzed above, it was identified as cleistanthin-B [26].

Compound 6, yellow crystal; m.p. $196 \sim 198^{\circ} \mathrm{C}$, molecular formula: $\mathrm{C}_{21} \mathrm{H}_{20} \mathrm{O}_{11} ;{ }^{1} \mathrm{H}$ NMR $\left(\mathrm{CD}_{3} \mathrm{OD}, 500 \mathrm{MHz}\right) \delta$ : $8.03\left(2 \mathrm{H}, \mathrm{d}, J=8.6 \mathrm{~Hz}, \mathrm{H}-2^{\prime}, 6^{\prime}\right), 6.87(2 \mathrm{H}, \mathrm{d}, J=8.6 \mathrm{~Hz}$, H-3', 5'), 6.36(1H, d, $J=2.3 \mathrm{~Hz}, \mathrm{H}-8), 6.17(1 \mathrm{H}, \mathrm{d}, J=$ $2.3 \mathrm{~Hz}, \mathrm{H}-6), 5.23\left(1 \mathrm{H}, \mathrm{d}, J=7.4 \mathrm{~Hz}, \mathrm{H}-1{ }^{\prime \prime}\right) ;{ }^{13} \mathrm{C}$ NMR $\left(\mathrm{CD}_{3} \mathrm{OD}, 125 \mathrm{MHz}\right) \delta: 178.1$ (C-4), 164.1 (C-7), 161.2 (C-5),160.2 (C-4'), 157.6 (C-2), 157.2 (C-9), 134.0 (C-3), 130.9 (C-2'), 130.9 (C-6'), 120.9 (C-1'), 114.7 (C-3'), 114.7 (C-5'), 104.2 (C-10), 98.7 (C-6), 93.5 (C-8), 102.7 (C-1"), 74.4 (C-2"), 77.0 (C-3"), 70.0 (C-4"), 76.7 (C-5"), 61.2 (C-6"). As analyzed above, it was identified as kaempferol-3-O- $\beta$ - $D$-glucopyranoside [27].

Compound 7, white power; m.p. $140 \sim 142^{\circ} \mathrm{C}$; molecular formula: $\mathrm{C}_{27} \mathrm{H}_{30} \mathrm{O}_{13} ;{ }^{1} \mathrm{H}$ NMR $\left(\mathrm{CD}_{3} \mathrm{OD}, 500 \mathrm{MHz}\right) \delta$ : $7.38(1 \mathrm{H}, \mathrm{s}, \mathrm{H}-5), 6.40\left(2 \mathrm{H}, \mathrm{s}, \mathrm{H}-2^{\prime}, \mathrm{H}-6^{\prime}\right), 5.94(2 \mathrm{H}, \mathrm{dd}$, $\left.J=1.2 \mathrm{~Hz}, J=1.2 \mathrm{~Hz}, \mathrm{OCH}_{2} \mathrm{O}\right), 5.05(1 \mathrm{H}, \mathrm{d}, J=4.9 \mathrm{~Hz}$, $\mathrm{H}-4), 4.69(1 \mathrm{H}, \mathrm{dd}, J=7.7 \mathrm{~Hz}, J=3.5 \mathrm{~Hz}, \mathrm{H}-3 \mathrm{a} \alpha), 4.54$ $(1 \mathrm{H}, \mathrm{d}, J=2.3 \mathrm{~Hz}, \mathrm{H}-1), 4.39(1 \mathrm{H}, \mathrm{d}, J=3.7 \mathrm{~Hz}, \mathrm{H}-1$ "), $4.21(1 \mathrm{H}, \mathrm{t}, J=9.5 \mathrm{~Hz}, \mathrm{H}-3 \mathrm{a} \beta), 3.90(1 \mathrm{H}, \mathrm{d}, J=7.5 \mathrm{~Hz}$, H-6"), 3.88 (1H, d, J = $7.5 \mathrm{~Hz}, \mathrm{H}-6$ "), 3.72 (6H, s, 3', 5'OMe), $3.35(4 \mathrm{H}, \mathrm{m}, \mathrm{H}-2$ " 5"), $3.03(1 \mathrm{H}, \mathrm{dd}, J=9.7 \mathrm{~Hz}$, $J=2.6 \mathrm{~Hz}, \mathrm{H}-2), 2.95(1 \mathrm{H}, \mathrm{m}, \mathrm{H}-3) ;{ }^{13} \mathrm{C} \mathrm{NMR}\left(\mathrm{CD}_{3} \mathrm{OD}\right.$, $125 \mathrm{MHz}$ ) $\delta: 175.7$ (C-2a), 147.7 (C-3', 5'), 147.2 (C-6, 7), 134.4 (C-4'), 132.1 (C-1'), 131.2 (C-10), 131.1 (C-9), 108.8 (C-8), 108.3 (C-2', 6'), 108.2 (C-5), 102.3 (C-1"), $101.2\left(\mathrm{OCH}_{2} \mathrm{O}\right), 79.0$ (C-5"), 76.8 (C-3"), 73.8 (C-2"), 71.5 (C-4), 70.3 (C-3a), 70.2 (C-4"), 61.4 (C-6”), 55.5 (3', 5'- $\left.\mathrm{OCH}_{3}\right), 45.1(\mathrm{C}-2), 43.7(\mathrm{C}-1), 39.2(\mathrm{C}-3)$. As analyzed above, it was identified as 4'-demethylpodophyllotoxin4-O-glucoside [28].

Compound 8, yellow crystal; m.p. $188 \sim 190^{\circ} \mathrm{C}$; molecular formula: $\mathrm{C}_{21} \mathrm{H}_{20} \mathrm{O}_{12} ;{ }^{1} \mathrm{H}$ NMR $\left(\mathrm{CD}_{3} \mathrm{OD}, 500\right.$ $\mathrm{MHz}) \delta: 7.61\left(1 \mathrm{H}, \mathrm{d}, J=1.8 \mathrm{~Hz}, \mathrm{H}-2^{\prime}\right), 6.77(1 \mathrm{H}, \mathrm{d}, J=$ $\left.8.6 \mathrm{~Hz}, \mathrm{H}-5^{\prime}\right), 6.49(2 \mathrm{H}, \mathrm{dd}, J=2.3 \mathrm{~Hz}, J=6.3 \mathrm{~Hz}, \mathrm{H}-$ $\left.6^{\prime}\right), 6.29(1 \mathrm{H}, \mathrm{d}, J=1.7 \mathrm{~Hz}, \mathrm{H}-8), 6.10(1 \mathrm{H}, \mathrm{d}, J=2.3$ $\mathrm{Hz}, \mathrm{H}-6), 5.16(1 \mathrm{H}, \mathrm{d}, J=7.5 \mathrm{~Hz}, \mathrm{H}-1 "), 3.10 \sim 3.63$ $(6 \mathrm{H}, \mathrm{m}, \mathrm{H}-2 " \sim 6 ") ;{ }^{13} \mathrm{C}$ NMR (CD $\left.\mathrm{OD}, 125 \mathrm{MHz}\right) \delta$ : 178.1 (C-4), 165.3(C-7), 161.7 (C-5),157.6 (C-2), 157.2 (C-9), 148.5 (C-4'), 144.6 (C-3') 134.2 (C-3), 121.8 (C6'), 121.7 (C-1' ), 116.1 (C-5'), 114.6 (C-2' ), 104.2 (C10), 102.9 (C-1"), 98.7 (C-6), 93.4 (C-8), 77.1 (C-3”),
76.8 (C-2"), 74.4 (C-4"), 69.8 (C-5"), 61.2 (C-6"). As analyzed above, it was identified as quercetin-3-O- $\beta-D$ glucopyranoside [29].

Compound 9, white crystal; m.p. $225 \sim 228^{\circ} \mathrm{C}$; molecular formula: $\mathrm{C}_{34} \mathrm{H}_{42} \mathrm{O}_{18} ;{ }^{1} \mathrm{H}$ NMR (DMSO- $d_{6}, 500 \mathrm{MHz}$ ) $\delta: 7.21(1 \mathrm{H}, \mathrm{s}, \mathrm{H}-5), 6.65\left(2 \mathrm{H}, \mathrm{s}, \mathrm{H}-2^{\prime}, \mathrm{H}-6^{\prime}\right), 5.95(2 \mathrm{H}, \mathrm{d}$, $\left.J=6.3 \mathrm{~Hz}, \mathrm{OCH}_{2} \mathrm{O}\right), 5.83(1 \mathrm{H}, \mathrm{s}, \mathrm{H}-8), 5.36(1 \mathrm{H}, \mathrm{d}, J=$ $2.6 \mathrm{~Hz}, \mathrm{H}-1), 5.14(1 \mathrm{H}, \mathrm{d}, J=5.2 \mathrm{~Hz}, \mathrm{H}-3 \mathrm{a} \beta), 4.71(1 \mathrm{H}$, $\mathrm{d}, J=2.3 \mathrm{~Hz}, \mathrm{H}-4), 4.07(1 \mathrm{H}, \mathrm{d}, J=4.6 \mathrm{~Hz}, \mathrm{H}-3 \mathrm{a} \alpha), 3.76$ (6H, s, 3', 5'-OMe), 3.68 (3H, s, 4'-OMe), $2.92(1 \mathrm{H}, \mathrm{m}$, $\mathrm{H}-3), 3.20 \sim 3.18(1 \mathrm{H}, \mathrm{m}, \mathrm{H}-2)$, Glc(inner): $5.13(1 \mathrm{H}, \mathrm{d}, J$ $\left.=5.8 \mathrm{~Hz}, \mathrm{H}-1^{\prime}\right), 4.49\left(1 \mathrm{H}, \mathrm{d}, J=7.5 \mathrm{~Hz}, \mathrm{H}-2^{\prime}\right), 3.90(1 \mathrm{H}$, t, $\left.J=9.5 \mathrm{~Hz}, \mathrm{H}-3^{\prime}\right), 3.52 \sim 3.49\left(1 \mathrm{H}, \mathrm{m}, \mathrm{H}-4^{\prime}\right), 4.56 \sim 4.49$ $\left(1 \mathrm{H}, \mathrm{m}, \mathrm{H}-5^{\prime}\right), 4.62\left(1 \mathrm{H}, \mathrm{d}, J=10.3 \mathrm{~Hz}, \mathrm{H}-6^{\prime}\right), 4.44 \sim 4.33$ $\left(1 \mathrm{H}, \mathrm{m}, \mathrm{H}-6^{\prime}\right)$; Glc (terminal): $4.81(1 \mathrm{H}, \mathrm{d}, J=4.0 \mathrm{~Hz}$, H-1"), $3.07(1 \mathrm{H}, \mathrm{dd}, J=8.6 \mathrm{~Hz}, \mathrm{H}-2 "), 3.52 \sim 3.41(1 \mathrm{H}$, m, H-3"), $3.90(1 \mathrm{H}, \mathrm{t}, J=9.5 \mathrm{~Hz}, \mathrm{H}-4$ "), $3.42(1 \mathrm{H}, \mathrm{m}, \mathrm{H}-$ 5"), 4.57 (1H, d, $J=4.6 \mathrm{~Hz}, \mathrm{H}-6$ "), 4.42 4.38 $(1 \mathrm{H}, \mathrm{m}, \mathrm{H}-$ $6 ") ;{ }^{13} \mathrm{C}$ NMR (DMSO- $\left.d_{6}, 125 \mathrm{MHz}\right) \delta: 178.4(\mathrm{C}-12)$, 153.4 (C-3', 5'), 146.6 (C-6), 146.0 (C-7), 138.3 (C-1'), 136.4 (C-4'), 132.9 (C-10), 132.8 (C-9), 107.8 (C-8), 106.9 (C-2', 6'), $106.3(\mathrm{C}-5), 101.2\left(\mathrm{OCH}_{2} \mathrm{O}\right), 76.8(\mathrm{C}-4)$, $68.5(\mathrm{C}-11), 60.5\left(4^{\prime}-\mathrm{OCH}_{3}\right), 56.4\left(3^{\prime}, 5^{\prime}-\mathrm{OCH}_{3}\right)$; Glc (inner): 104.1 (C-1'), 73.9 (C-2'), 77.4 (C-3', 5'), 70.8 (C4'), 69.3 (C-6'); Glc (terminal): 103.6 (C-1"), 74.2 (C-2"), 77.3 (C-3", 5"), 70.4 (C-4"), 61.4 (C-6"). As analyzed above, it was identified as icropodophyllotoxin-4-O- $\beta-D$ glucopyranosyl-(1-6)- $\beta$-D-glucopyranoside $[23,30]$.

Compound 10, yellow power; m.p. $306 \sim 308^{\circ} \mathrm{C}$; molecular formula: $\mathrm{C}_{15} \mathrm{H}_{10} \mathrm{O}_{7} ;{ }^{1} \mathrm{H}$ NMR $\left(\mathrm{CD}_{3} \mathrm{OD}, 500 \mathrm{MHz}\right)$ $\delta: 7.64\left(1 \mathrm{H}, \mathrm{d}, J=2.3 \mathrm{~Hz}, \mathrm{H}-2^{\prime}\right), 7.53(1 \mathrm{H}, \mathrm{dd}, J=8.6$ $\left.\mathrm{Hz}, J=2.3 \mathrm{~Hz}, \mathrm{H}-6^{\prime}\right), 6.78\left(1 \mathrm{H}, \mathrm{d}, J=8.6 \mathrm{~Hz}, \mathrm{H}-5^{\prime}\right), 6.28$ $(1 \mathrm{H}, \mathrm{d}, J=2.3 \mathrm{~Hz}, \mathrm{H}-8), 6.08(1 \mathrm{H}, \mathrm{d}, J=1.8 \mathrm{~Hz}, \mathrm{H}-6)$; ${ }^{13} \mathrm{C}$ NMR $\left(\mathrm{CD}_{3} \mathrm{OD}, 125 \mathrm{MHz}\right) \delta: 175.9(\mathrm{C}-4), 164.3(\mathrm{C}-$ 7), 161.2 (C-5), 156.9 (C-9), 147.4 (C-2), 146.6 (C-3'), 144.9 (C-4'), 135.9 (C-3), 122.8 (C-1'),120.3 (C-6'), 114.9 (C-5'), 114.6 (C-2'), 103.1 (C-10), 97.9 (C-6), 93.1 (C-8). As analyzed above, it was identified as quercetin $[31,32]$.

Compound 11, white power; m.p. $297 \sim 300^{\circ} \mathrm{C}$; molecular formula: $\mathrm{C}_{35} \mathrm{H}_{60} \mathrm{O}_{6} ;{ }^{1} \mathrm{H}$ NMR(Pyridine- $d_{5}, 500 \mathrm{MHz}$ ) $\delta: 5.35(1 \mathrm{H}, \mathrm{s}, \mathrm{H}-6), 5.06 \sim 5.07\left(1 \mathrm{H}, \mathrm{m}, \mathrm{H}-1^{\prime}\right), 2.12 \sim 4.60$ (10H, m, GluH), 0.85 1.13 (18H, m, H-CH $), 0.66(3 \mathrm{H}$, s, H-29); ${ }^{13} \mathrm{C}$ NMR (Pyridine- $\left.d_{5}, 125 \mathrm{MHz}\right) \delta: 139.0$ (C5), 120.2 (C-6), 100.8 (C-1'), 77.0 (C-5'), 76.9 (C-3'), 76.4 (C-3), 73.7 (C-2'), 70.0 (C-4'), 61.2 (C-6'), 55.2 (C-14), 55.1 (C-17), 54.6 (C-9), 54.4 (C-24), 49.7 (C-4), 48.7 (C13), 44.4 (C-12), 40.8 (C-1), 39.1 (C-10), 38.3 (C-20), 38.1 (C-22), 37.7 (C-7), 35.8 (C-8), 35.3 (C-2), 34.7 (C25), 32.5 (C-16), 30.5 (C-23), 30.4 (C-15), 28.7 (C-28), 27.8 (C-11), 27.6 (C-19), 26.9 (C-21), 24.7 (C-27), 24.0 (C-26), 22.8 (C-29), 16.0 (C-18). As analyzed above, it was identified as daucosterol [33].

Compound 12, colorless acerate crystal; m.p. 183 185 C; molecular formula: $\mathrm{C}_{22} \mathrm{H}_{20} \mathrm{O}_{8} ;{ }^{1} \mathrm{H} \mathrm{NMR}\left(\mathrm{CD}_{3} \mathrm{COCD}_{3}\right.$, 
$500 \mathrm{MHz}) \delta: 7.43(1 \mathrm{H}, \mathrm{s}, \mathrm{H}-5), 6.83(1 \mathrm{H}, \mathrm{s}, \mathrm{H}-8), 6.49$ $\left(2 \mathrm{H}, \mathrm{s}, \mathrm{H}-2^{\prime}, 6^{\prime}\right), 6.15\left(2 \mathrm{H}, \mathrm{s}, \mathrm{OCH}_{2} \mathrm{O}\right), 4.91(1 \mathrm{H}, \mathrm{d}, J=$ $4.0 \mathrm{~Hz}, \mathrm{H}-1), 4.49(1 \mathrm{H}, \mathrm{t}, J=7.7 \mathrm{~Hz}, \mathrm{H}-3 \mathrm{a} \alpha), 4.34(1 \mathrm{H}$, t, $J=9.5 \mathrm{~Hz}, \mathrm{H}-3 \mathrm{a} \beta), 3.70(6 \mathrm{H}, \mathrm{s}, 3$ ', 5'-OM e), $3.68(3 \mathrm{H}$, s, 4'-OMe), 3.65 3.49 (1H, m, H-3), $3.63(1 \mathrm{H}, \mathrm{d}, J=3.5$ $\mathrm{Hz}, \mathrm{H}-2) ;{ }^{13} \mathrm{C}$ NMR $\left(\mathrm{CD}_{3} \mathrm{COCD}_{3}, 125 \mathrm{~Hz}\right) \delta: 192.2(\mathrm{C}-4$ ), 173.1 (C-2a ), 153.1 (C-5'), 153.1 (C-7), 153.0 (C-3'), 148.0 (C-6), 141.9 (C-9), 137.7 (C-4'), 133.1 (C-1'), 128.6 (C-10), 109.6 (C-8), 108.1 (C-2'), $108.1\left(\mathrm{C}^{\prime} 6^{\prime}\right), 105.0$ (C5), $102.7\left(-\mathrm{OCH}_{2} \mathrm{O}-\right), 66.6$ (C-3a ), 59.6 (4'-OMe), 55.5 (3', 5'-OMe), 45.8 (C-2), 44.6 (C-1), 43.4 (C-3). As analyzed above, it was identified as podophyllotoxone $[34,35]$.

Compound 13, colorless crystal; m.p. $200 \sim 202^{\circ} \mathrm{C}$; molecular formula: $\mathrm{C}_{8} \mathrm{H}_{8} \mathrm{O}_{4} ;{ }^{1} \mathrm{H}$ NMR $\left(\mathrm{CD}_{3} \mathrm{COCD}_{3}, 500\right.$ $\mathrm{MHz}) \delta: 7.60(1 \mathrm{H}, \mathrm{dd}, \mathrm{J}=8.0 \mathrm{~Hz}, \mathrm{~J}=1.7 \mathrm{~Hz}, \mathrm{H}-6), 7.57$ $(1 \mathrm{H}, \mathrm{d}, \mathrm{J}=1.7 \mathrm{~Hz}, \mathrm{H}-2), 6.92(1 \mathrm{H}, \mathrm{d}, \mathrm{J}=8.0 \mathrm{~Hz}, \mathrm{H}-5)$, $3.89\left(3 \mathrm{H}, \mathrm{s}, \mathrm{OCH}_{3}\right) ;{ }^{13} \mathrm{C} \operatorname{NMR}\left(\mathrm{CD}_{3} \mathrm{COCD}_{3}, 125 \mathrm{MHz}\right) \delta$ : $166.7(\mathrm{C}=\mathrm{O}), 152.0(\mathrm{C}-3), 147.2(\mathrm{C}-4), 124.0(\mathrm{C}-6)$, $122.0(\mathrm{C}-1), 114.6(\mathrm{C}-5), 112.6(\mathrm{C}-2), 55.4\left(-\mathrm{OCH}_{3}\right)$. As analyzed above, it was identified as vanillic acid [36].

Compound 14, colorless power; m.p. $238 \sim 240^{\circ} \mathrm{C}$; molecular formula: $\mathrm{C}_{21} \mathrm{H}_{20} \mathrm{O}_{7} ;{ }^{1} \mathrm{H}$ NMR $\left(\mathrm{CD}_{3} \mathrm{COCD}_{3}\right.$, $500 \mathrm{MHz}) \delta: 6.75(1 \mathrm{H}, \mathrm{s}, \mathrm{H}-5), 6.52(1 \mathrm{H}, \mathrm{s}, \mathrm{H}-8), 6.39$ $\left(2 \mathrm{H}, \mathrm{s}, \mathrm{H}-2^{\prime}, \mathrm{H}-6^{\prime}\right), 5.96\left(2 \mathrm{H}, \mathrm{d}, J=2.9 \mathrm{~Hz}, \mathrm{OCH}_{2} \mathrm{O}\right)$, $4.55(1 \mathrm{H}, \mathrm{d}, J=5.2 \mathrm{~Hz}, \mathrm{H}-1), 4.43(1 \mathrm{H}, \mathrm{dd}, J=8 \mathrm{~Hz}, J=$ $6.9 \mathrm{~Hz}, 3 \mathrm{a}-\alpha \mathrm{H}), 3.97(1 \mathrm{H}, \mathrm{dd}, J=10.3 \mathrm{~Hz}, J=8 \mathrm{~Hz}, 3 \mathrm{a}-$ $\beta \mathrm{H}), 3.69\left(6 \mathrm{H}, \mathrm{s}, 33^{\prime}-\mathrm{OM}\right.$ e, 5'-OM e), 3.12 3.09 (1H, m, $4-\alpha \mathrm{H}), 2.86 \sim 2.76(3 \mathrm{H}, \mathrm{m}, 4-\beta \mathrm{H}, \mathrm{H}-2, \mathrm{H}-3) ;{ }^{13} \mathrm{C} \mathrm{NMR}$ $\left(\mathrm{CD}_{3} \mathrm{COCD}_{3}, 125 \mathrm{MHz}\right) \delta: 174.8(\mathrm{C}-2 \mathrm{a}), 147.1\left(\mathrm{C}-3^{\prime}\right)$, 147.1 (C-5'), 147.0 (C-6), 146.6 (C-7), 131.8 (C-1'), 131.8 (C-4'), 131.4 (C-9), 129.3 (C-10), 110.1 (C-8), 108.8 (C5), 108.4 (C-2'), 108.2 (C-6'), $101.2\left(-\mathrm{OCH}_{2} \mathrm{O}-\right), 71.6(\mathrm{C}-$ 3a), 55.8 (3'-OMe, 5'-OMe), 46.9 (C-2), 43.6 (C-1), 32.9
(C-4), 32.6(C-3). As analyzed above, it was identified as 4'-demethyldeoxypodophyllotoxin [37].

Compound 15, colorless cubic crystal; m.p. 164 166 C; molecular formula: $\mathrm{C}_{12} \mathrm{H}_{22} \mathrm{O}_{11} ;{ }^{1} \mathrm{H}$ NMR $\left(\mathrm{D}_{2} \mathrm{O}, 500\right.$ $\mathrm{MHz}) \delta: 5.37(1 \mathrm{H}, \mathrm{d}, J=4 \mathrm{~Hz}, \mathrm{H}-1), 4.17(1 \mathrm{H}, \mathrm{d}, J=8.6$ $\left.\mathrm{Hz}, \mathrm{H}-3^{\prime}\right), 4.00\left(1 \mathrm{H}, \mathrm{t}, J=8.6 \mathrm{~Hz}, \mathrm{H}-5^{\prime}\right), 3.83 \sim 3.76(1 \mathrm{H}$, m, H-4'), 3.78 3.71 (5H, m, H-6, 6', 4'), $3.70(1 \mathrm{H}, \mathrm{dd}, J$ $=9.5 \mathrm{~Hz}, \mathrm{H}-5), 3.63\left(2 \mathrm{H}, \mathrm{s}, \mathrm{H}-1^{\prime}\right), 3.50(1 \mathrm{H}, \mathrm{dd}, J=3.8$ $\mathrm{Hz}, \mathrm{H}-3), 3.41(1 \mathrm{H}, \mathrm{t}, J=10 \mathrm{~Hz}, \mathrm{H}-4) ;{ }^{13} \mathrm{C}$ NMR $\left(\mathrm{D}_{2} \mathrm{O}\right.$, $125 \mathrm{MHz}) \delta$ : 103.7 (C-2'), 92.2 (C-1), $81.4\left(\mathrm{C}-3^{\prime}\right), 76.3$ (C-4'), 73.9 (C-5'), 72.5 (C-5), $72.4(\mathrm{C}-3), 71.1(\mathrm{C}-2), 69.2$ (C-4), 62.3 (C-1'), 61.0(C-6'), $60.3(\mathrm{C}-6)$. As analyzed above, it was identified as sucrose [38].

\section{Anticancer activity}

The potential effect of the extracts from $D$. versipellis was investigated on the viability of PC3, Bcap-37, BGC823 and NIH3T3 cells using MTT assay at the concentration of $20 \mu \mathrm{M}$, with ADM (adriamycin) [39] being used as the positive control $[40,41]$. MTT [3-(4, 5dimethylthiazol-2-yl)-2, 5-diphenyltetrazolium bromide] assay is a common method of measuring the proliferation of cells. The results are summarized in Table 1. It could be seen that PTO and DDPT possess potent activities against the three human cancer cell lines tested. The inhibitory ratios of PTO and DDPT at $72 \mathrm{~h}$ after treatment were $52.0 \%$ and $67.1 \%$ against PC3 cells, $42.1 \%$ and $56.6 \%$ on Bcap- 37 cells, $47.9 \%$ and $60.7 \%$ on BGC-823 cells, and $43.7 \%$ and $59.8 \%$ on NIH 3T3 cells. Further experiments found that proliferation of these three carcinoma cells were significantly inhibited by PTO and DDPT in a concentration-dependent manner, as shown in Figures 2 and 3. The $\mathrm{IC}_{50}$ values of PTO on PC3, Bcap-37 and BGC-823 cells were (17.8 \pm 1.0$)$

Table 1 Growth inhibition effect of various constituents of $D$. versipellis on different cells

\begin{tabular}{|c|c|c|c|c|}
\hline \multirow[t]{2}{*}{ Compound $(20 \mu \mathrm{M})$} & \multicolumn{4}{|c|}{ Growth inhibition (\%) } \\
\hline & PC3 & Bcap-37 & BGC-823 & NIT3T3 \\
\hline$\beta$-sitosterol & $14.7 \pm 8.5$ & $10.9 \pm 10.4$ & $19.5 \pm 9.3$ & $1.7 \pm 9.3$ \\
\hline 4'-demethylpodophyllotoxin & $60.5 \pm 5.2^{* *}$ & $56.7 \pm 9.1^{* *}$ & $56.9 \pm 12.4$ & $60.1 \pm 6.1^{* *}$ \\
\hline Kaempferol & $43.9 \pm 11.9^{* *}$ & $53.2 \pm 10.9^{* *}$ & $53.4 \pm 14.9$ & $39.2 \pm 8.2^{* *}$ \\
\hline picropodophyllotoxin-4-O-glucoside & $9.0 \pm 9.9$ & $7.4 \pm 9.3$ & $24.6 \pm 11.3^{* *}$ & $6.4 \pm 8.8$ \\
\hline kaempferol-3-O- $\beta$-D-glucopyranoside & $23.0 \pm 6.4^{* *}$ & $29.9 \pm 10.8^{* *}$ & $13.2 \pm 8.7$ & $23.0 \pm 7.9^{* *}$ \\
\hline 4'-demethylpodophyllotoxin-4-O-glucoside & $19.8 \pm 7.1^{* *}$ & $21.9 \pm 6.5^{* *}$ & $14.5 \pm 8.0$ & $6.5 \pm 7.7$ \\
\hline quercetin-3-O- $\beta$-D-glucopyranoside & $11.6 \pm 9.1$ & $15.2 \pm 10.1$ & $40.7 \pm 11.9^{* *}$ & $5.1 \pm 9.9$ \\
\hline icropodophyllotoxin-4-O- $\beta$-D-glucopyranosyl-(1 $\rightarrow 6)-\beta$-D-glucopyranoside. & $10.2 \pm 8.1$ & $23.9 \pm 10.2$ & $23.6 \pm 10.7^{* *}$ & $2.2 \pm 8.8$ \\
\hline Quercetin & $29.8 \pm 8.3$ & $39.0 \pm 13.3^{* *}$ & $22.1 \pm 4.3^{*}$ & $8.1 \pm 5.0$ \\
\hline Podophyllotoxone & $52.0 \pm 5.6^{* *}$ & $42.1 \pm 6.3^{* *}$ & $47.9 \pm 8.1$ & $43.7 \pm 6.2^{* *}$ \\
\hline vanillic acid & $29.2 \pm 3.9^{* *}$ & $30.3 \pm 10.9^{* *}$ & $28.5 \pm 12.3$ & $10.2 \pm 5.0^{*}$ \\
\hline 4'-demethyldeoxypodophyllotoxin & $67.1 \pm 3.4^{* *}$ & $56.6 \pm 12.3^{* *}$ & $60.7 \pm 9.8^{* *}$ & $59.8 \pm 3.5^{* *}$ \\
\hline ADM & $93.2 \pm 1.6$ & $90.6 \pm 1.2^{* *}$ & $98.3 \pm 4.0^{* *}$ & $97.5 \pm 1.7^{* *}$ \\
\hline
\end{tabular}

All the values are expressed as mean $\pm S D(n=6) .{ }^{*} P<0.05,{ }^{* *} P<0.01$ compared with control. 


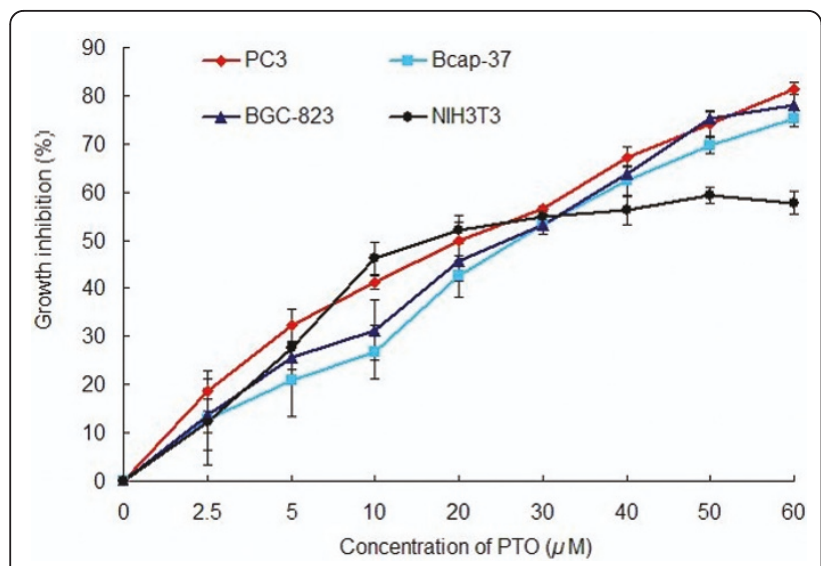

Figure 2 Effect of PTO on proliferation of tumor cells. After PC3, Bcap-37, BGC-823 and NIT3T3 cells were treated with PTO for $72 \mathrm{~h}$ in the concentrations varied from 2.5 to $60 \mu \mathrm{M}$, growth inhibition of those tumor cells was detected by MTT assay. Data are presented as means $\pm S D, n=4$.

$\mu \mathrm{M},(21.1 \pm 1.8) \mu \mathrm{M},(19 \pm 1.6) \mu \mathrm{M}$ respectively, while for DDPT, the $\mathrm{IC}_{50}$ values were $(10.6 \pm 1.5) \mu \mathrm{M},(13.2 \pm 0.5)$ $\mu \mathrm{M},(11.5 \pm 0.6) \mu \mathrm{M}$, respectively, which were both lower than that on NIH 3T3 cells $[(24.2 \pm 2.1) \mu \mathrm{M}$ for PTO; $(16.2 \pm 9.9) \mu \mathrm{M}$ for DDPT]. The results showed that PTO and DDPT had more potent activities against PC3, Bcap-37 and BGC-823 cells than on NIH3T3 cells. Besides, the inhibitory effect on tumor cells of DDPT was stronger than that of PTO.

To determine whether the growth inhibitory activity of PTO and DDPT were related to the induction of apoptosis, the morphological character changes of PC3 and Bcap-37 cells were investigated using the $\mathrm{AO} / \mathrm{EB}$

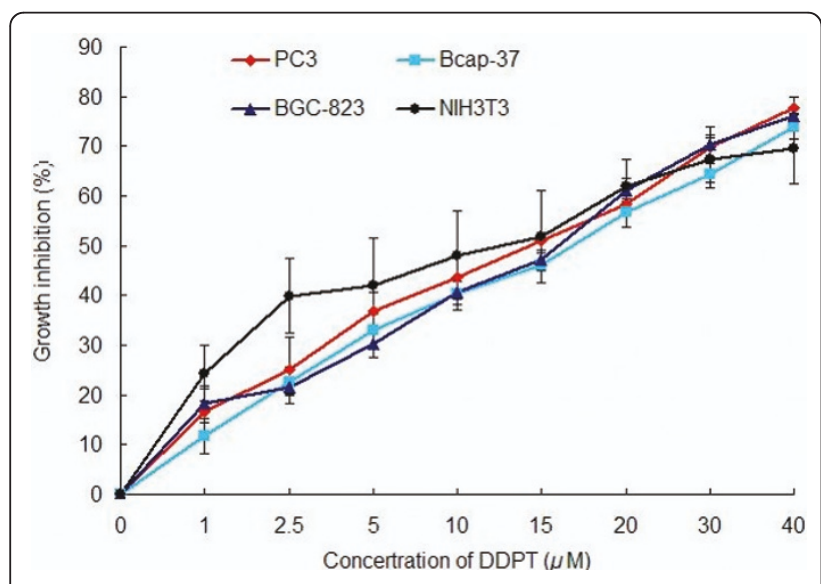

Figure 3 Effect of DDPT on proliferation of tumor cells. After PC3, Bcap-37, BGC-823 and NIT3T3 cells were treated with DDPT for $72 \mathrm{~h}$ in the concentration varied from 1 to $40 \mu \mathrm{M}$, growth inhibition of those tumor cells was detected by MTT assay. Data are presented as means $\pm S D, n=4$. staining and Hoechst 33258 staining under fluorescence microscopy.

Since acridine orange (AO) was a vital dye that could stain nuclear DNA across an intact cell membrane and ethidium bromide (EB) could only stain cells that had lost membrane integrity. Thus, live cells will be uniformly stained green, early apoptotic cells will be densely stained as green yellow or displayed green yellow fragments, while late apoptotic cells will be densely stained as orange or displayed orange fragments, and necrotic cells will be stained with orange with no condensed chromatin could be found by the AO/EB doubly staining. After tumor cells were treated with PTO and DDPT $(20 \mu \mathrm{M})$ for 24 , $48 \mathrm{~h}$, the morphological changes were analyzed. As shown in Figure 4, green live PC3 and Bcap-37 cells with normal morphology were seen in the negative control group (Figure 4A and 4A'). In contrast, early apoptotic cells with yellow green dots in PC3 cell nuclei and late apoptotic cells with orange dots in Bcap-37 cell nuclei could be seen in the positive control group (Figure 4D and 4D'), meanwhile bright green early apoptotic cells with nuclear margination and chromatin condensation occurred in the experimental group with 24 h of treatment (Figure 4B and 4E) and orange colored apoptotic

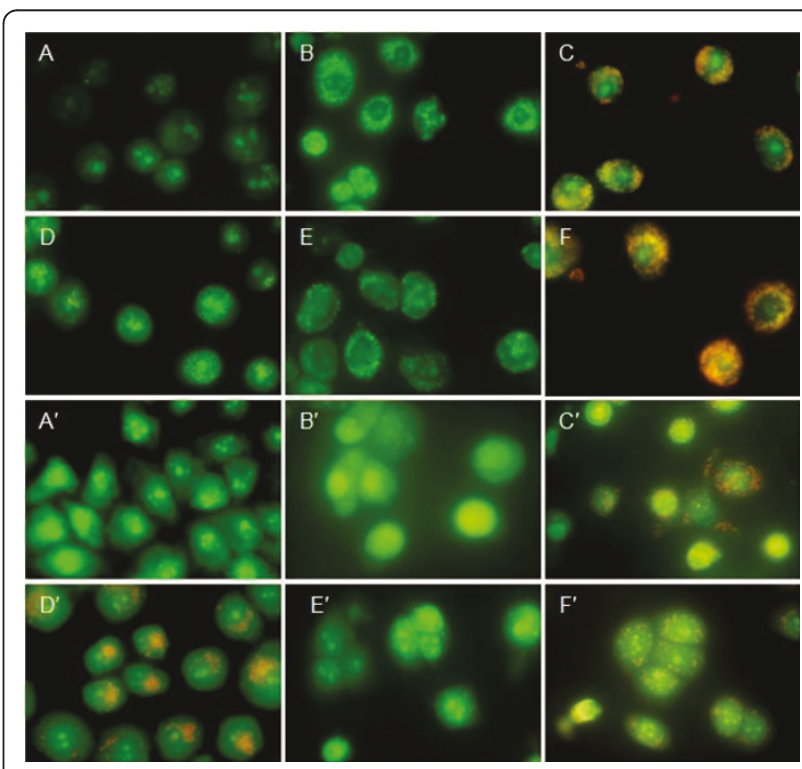

Figure 4 Nuclei morphological changes during PTO and DDPTinduced apoptosis in tumor cells detected by AO/EB staining. After treated with PTO and DDPT at $20 \mu \mathrm{M}, \mathrm{PC} 3$ and Bcap-37 cells were stained with AO/EB $(100 \mu \mathrm{g} / \mathrm{mL})$ and observed under fluorescence microscopy. For PC3 cells group, A: negative control (without treatment); D: positive control, treated with HCPT $(20 \mu \mathrm{M})$ for $24 \mathrm{~h}$; B and C: treated with PTO $(20 \mu \mathrm{M})$ for $24,48 \mathrm{~h}$; E and F, treated with DDPT $(20 \mu \mathrm{M})$ for $24,48 \mathrm{~h}$, respectively. For Bcap-37 cells group, $A^{\prime}$ : negative control; D': positive control, treated by HCPT $(20 \mu \mathrm{M})$ for $24 \mathrm{~h}$; $\mathrm{B}^{\prime}$ and $\mathrm{C}^{\prime}$ : treated with PTO $(20 \mu \mathrm{M})$ for 24 , 48 h; E'and F': treated with DDPT $(20 \mu \mathrm{M})$ for $24,48 \mathrm{~h}$, respectively. 
cells with apoptotic bodies and chromatin fragmentation could be seen when PTO and DDPT were applied for 48 h (Figure 4E and 4F). Similarly, morphological changes of Bcap-37 cell apoptosis were also observed under microscope (Figure 4B', 4C', 4E', and 4F'). The results suggested that PTO and DDPT were able to induce apoptosis in PC3 and Bcap-37 cells.

Hoechst 33258 staining was also carried out to investigate the apoptosis induction of PTO and DDPT (20 $\mu \mathrm{M})$ on PC3 and Bcap-37 cells. Membrane-permeable Hoechst 33258 was a blue fluorescent dye and stained the cell nucleus. When cells were treated with Hoechst 33258 , live cells with uniformly light blue nuclei were observed under fluorescence microscope, while apoptotic cells exhibited bright blue because of karyopyknosis and chromatin condensation, and the nuclei of dead cells could not be stained. The experimental results were shown in Figure 5. Compared with the negative control (Figure 5A and 5A'), a part of cells with smaller nuclei and condensed staining appeared in the positive control group (Figure 5D and 5D'). After treated with PTO and DDPT for a given time, some PC3 cell nuclei became pyknotic (shrunken and dark), as shown in

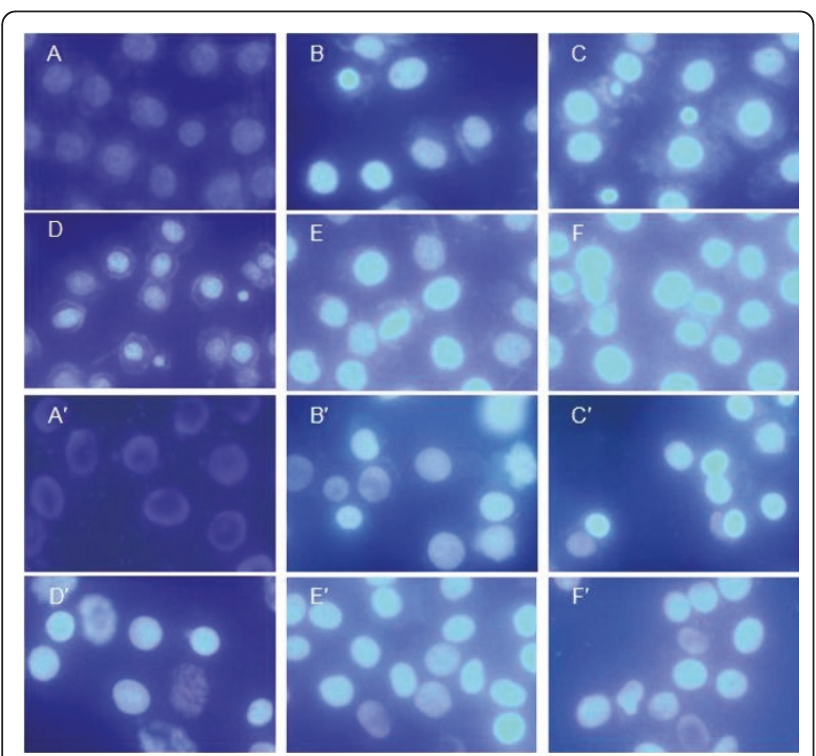

Figure 5 Nuclei morphological changes during PTO and DDPTinduced apoptosis in tumor cells detected by Hoechst 33258 staining. Tumor cells treated with PTO and DDPT $(20 \mu \mathrm{M})$ were stained by Hoechst 33258 and observed under fluorescence microscopy. For PC3 cells group, A: negative control (without treatment); D: positive control, treated with HCPT $(20 \mu \mathrm{M})$ for $24 \mathrm{~h}$; B and C: treated with PTO $(20 \mu \mathrm{M})$ for $24,48 \mathrm{~h}$; E and F: treated with DDPT $(20 \mu \mathrm{M})$ for $24,48 \mathrm{~h}$, respectively. For Bcap-37 cells group, $A^{\prime}$ : negative control (without treatment); D': positive control, treated with HCPT $(20 \mu \mathrm{M})$ for $24 \mathrm{~h}$; $\mathrm{B}^{\prime}$ and $\mathrm{C}^{\prime}$ : treated with PTO (20 $\mu \mathrm{M})$ for 24, $48 \mathrm{~h}$; $\mathrm{E}^{\prime}$ and $\mathrm{F}^{\prime}$ : treated with DDPT $(20 \mu \mathrm{M})$ for 24, $48 \mathrm{~h}$, respectively.
Figure 5B, 5C, 5E and 5F. Besides, Bcap-37 cells treated with PTO and DDPT for $24 \mathrm{~h}$ had no obvious morphologic changes (Figure 5B' and 5E'), but most cell nuclei appeared to be highly condensed (brightly stained) after $48 \mathrm{~h}$ of treatment (Figure $5 \mathrm{C}^{\prime}$ and $\mathrm{F}^{\prime}$ ). The results once again indicated that PTO and DDPT could induce apoptosis in PC3 and Bcap-37 cells.

TUNEL assay was further carried out to confirm the cell apoptosis inducing activities of PTO and DDPT.

TUNEL (Terminal deoxynucleotidyl Transferase Biotin-dUTP Nick End Labeling) is a popular method for identifying apoptotic cells in situ by detecting DNA fragmentation. Due to degradation of DNA that resulted from the activation of $\mathrm{Ca} / \mathrm{Mg}$ dependent endonucleases in apoptotic cells, DNA cleavage occurred and led to breaking of strand within the DNA. These strand breaks of cleaved DNA could be identified by terminal deoxynucleotidyl transferase $(\mathrm{TdT})$ that catalyzed the addition of biotin-dUTP. The biotin-labeled cleavage sites were then detected by reaction with streptavidin-HRP and visualized by DAB indicating a brown color. As shown in Figure 6, most nuclei were stained as a discernible brown in the treatment groups with $\mathrm{HCPT}$ (Figure 6C and $6 \mathrm{C}^{\prime}$ ), PTO (Figure $6 \mathrm{~B}$ and $6 \mathrm{~B}^{\prime}$ ), and DDPT (Figure 6D and 6D') compared with the control (Figure 6A and $\left.6 \mathrm{~A}^{\prime}\right)$.

In addition, the apoptosis ratios induced by PTO and DDPT caused apoptosis in tumor cells was quantitatively assessed by flow cytometry. In the early stages of apoptosis, phosphatidylserine (PS) was translocated from the inside of the cell membrane to the outside. Annexin V, a calcium dependent phospholipid-binding protein associated with a high affinity for phosphatidylserine, was used to detect early apoptotic cells. PI (Propidine Iodide) was a red fluorescent dye and stained cells that had lost membrane integrity. So, cells stained with FITC-annexin $\mathrm{V}$ and PI were discriminated necrotic cells (Q1, Annexin $\left.{ }^{-} / \mathrm{PI}^{+}\right)$, late apoptotic cells $\left(\mathrm{Q} 2\right.$, Annexin $\left.^{+} / \mathrm{PI}^{+}\right)$, intact cells $(\mathrm{Q} 3$, Annexin ${ }^{-} / \mathrm{PI}^{-}$) and early apoptotic cells (Q4, Annexin $\left.{ }^{+} / \mathrm{PI}^{-}\right)$. As shown in Figure $7, \mathrm{PTO}$ and DDPT $(20 \mu \mathrm{M})$ could induce apoptosis of PC3 cells, and highest apoptosis ratios, $12.0 \%$ and $14.1 \%$ for PTO and DDPT respectively, were obtained after $72 \mathrm{~h}$ of treatment at a concentration of $20 \mu \mathrm{M}$. Furthermore, as shown in Figure 8, the early (Q4) and late (Q2) apoptosis of PC3 cells which treated with PTO and DDPT increased gradually in a time-dependent manner. The late apoptotic ratio of cells increased to approximately $11.0 \%$ at $72 \mathrm{~h}$ after treatment of PTO (20 $\mu \mathrm{M})$, which was close to that of positive control HCPT (11.8\%). And the highest rate of early apoptosis was $7.0 \%$ when cells were treated with DDPT at the concentration of $20 \mu \mathrm{M}$ for $72 \mathrm{~h}$. 


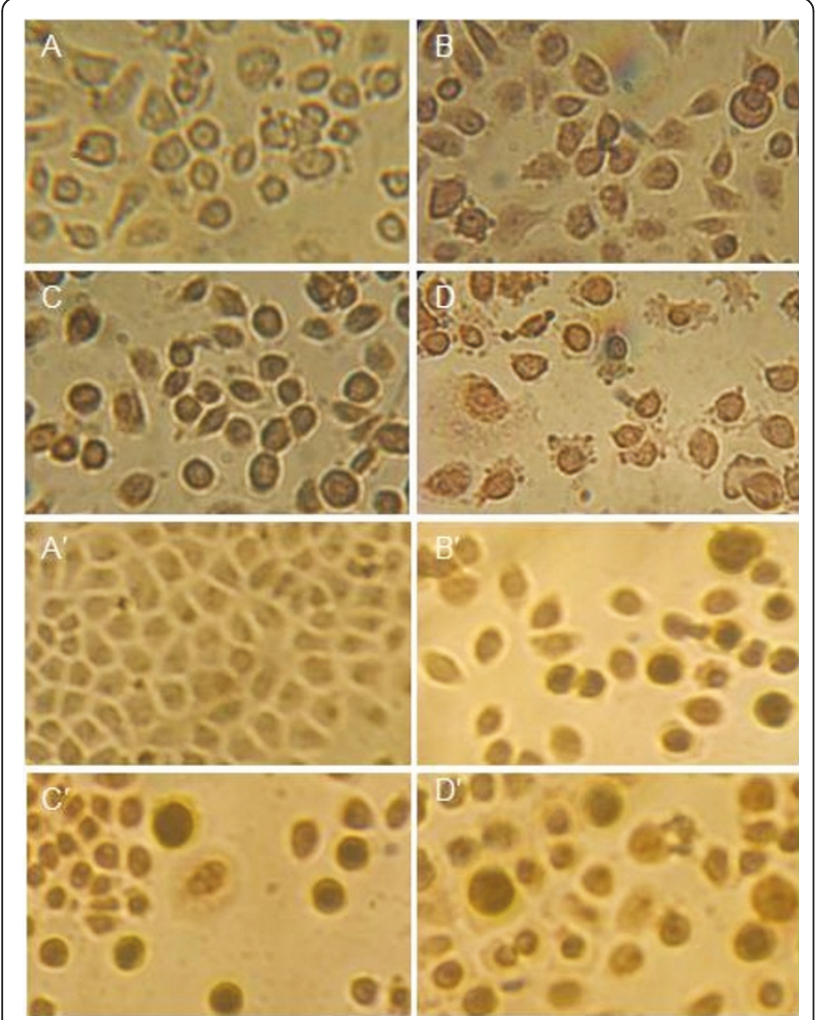

Figure 6 Nuclei morphological changes during PTO and DDPTinduced apoptosis in PC3 and Bcap-37 cells detected by TUNEL assay. Tumor cells treated with PTO and DDPT (20 $\mu \mathrm{M})$ were assayed by TUNEL and observed under light microscopy. For PC3 cells group, A: negative control (without treatment); C: positive control, treated with HCPT $(20 \mu \mathrm{M})$ for $24 \mathrm{~h}$; B and D: treated with PTO and DDPT $(20 \mu \mathrm{M})$ for $24 \mathrm{~h}$; For Bcap-37 cells group, A': negative control (without treatment); $C^{\prime}$ : positive control, treated with HCPT $(20 \mu \mathrm{M})$ for $24 \mathrm{~h} ; \mathrm{B}^{\prime}$ and $\mathrm{D}^{\prime}$ : treated with PTO and DDPT $(20 \mu \mathrm{M})$ for $24 \mathrm{~h}$.

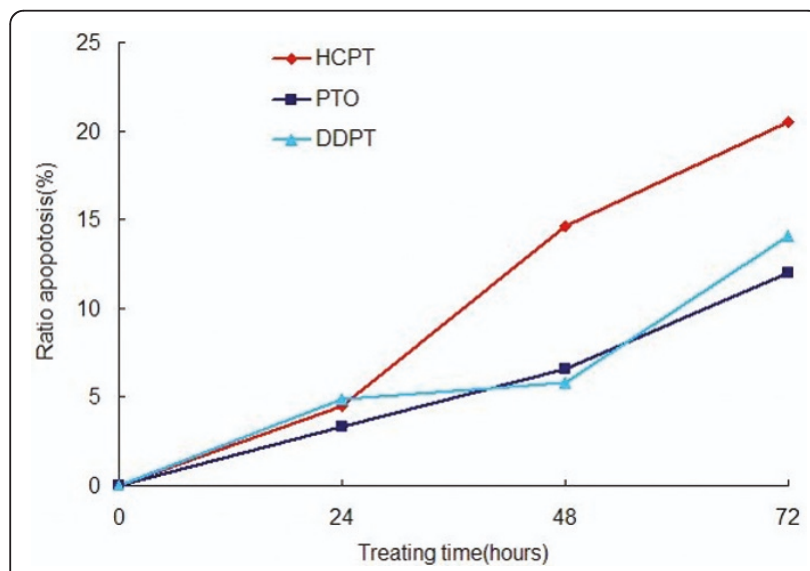

Figure 7 The apoptosis ratios of PC3 cells treated with PTO and DDPT $(20 \mu \mathrm{M})$ assessed by flow cytometry. These cells were treated with HCPT, PTO and DDPT $(20 \mu \mathrm{M})$ for 24,48 and $72 \mathrm{~h}$.

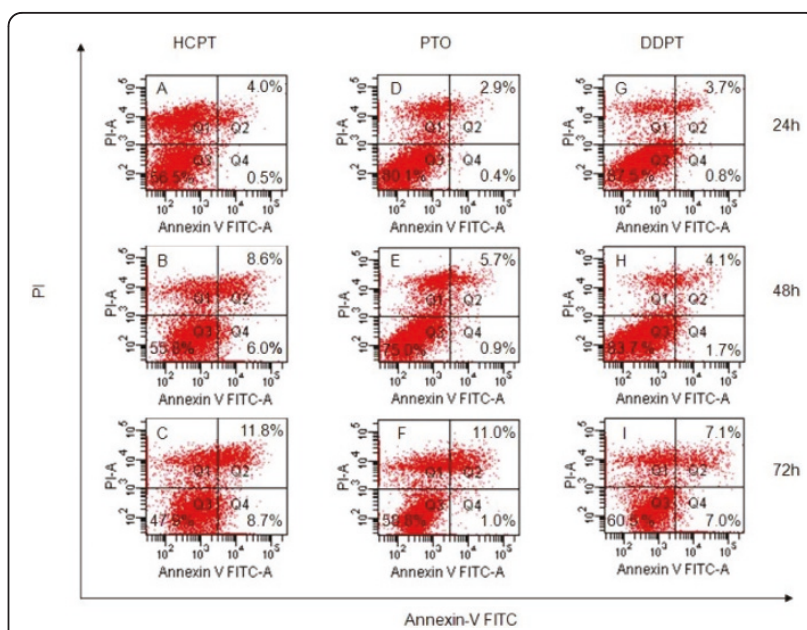

Figure 8 Flow cytometry analysis for apoptosis inducing activities of PTO and DDPT on PC3 cells. The appearance of apoptosis cells was detected by flow cytometry using Annexin V/PI staining. In the figure, A, B and C: treated with HCPT $(20 \mu \mathrm{M})$ for 24 , 48 and $72 \mathrm{~h}$; D, E and F: treated with PTO $(20 \mu \mathrm{M})$ for 24,48 and 72 h; $\mathrm{G}, \mathrm{H}$ and I: treated with DDPT $(20 \mu \mathrm{M})$ for 24,48 and $72 \mathrm{~h}$.

In summary, these results indicated that inhibitive effects observed in response to PTO and DDPT were associated with induction of apoptotic cell death.

\section{Conclusions}

Dysosma versipellis (Hance) M. Cheng, an important medicinal plant species, is considered 'endangered' by the China Species Red List and has been considered as vulnerable by the IUCN due to its rapid decline $[42,43]$. Therefore, studies on the chemical constituents from $D$. versipellis and their biological activities have assumed significance for the rational development and utilization of this plant. In our study, fifteen compounds were extracted and identified from $D$. versipellis grown in Guizhou province, and the cell growth inhibition effects of these constituents on PC3, Bcap-37, and BGC-823 cells were carried out by MTT assay. Among these compounds, PTO, which was extracted from $D$. versipellis for the first time, together with DDPT showed potent activities on PC3, Bcap-37, and BGC-823 cells in a dose-dependent manner. And the $\mathrm{IC}_{50}$ values of PTO and DDPT on three cell lines were $(17.8 \pm 1.0) \mu \mathrm{M},(21.1$ $\pm 1.8) \mu \mathrm{M},(19 \pm 1.6) \mu \mathrm{M}$ and $(10.6 \pm 1.5) \mu \mathrm{M},(13.2 \pm 0.5)$ $\mu \mathrm{M},(11.5 \pm 0.6) \mu \mathrm{M}$, respectively.

The apoptosis inducing activities of PTO and DDPT on $\mathrm{PC} 3$ and Bcap-37 cells were investigated through AO/EB staining, Hoechst 33258 staining, TUNEL and flow cytometry analysis assay. The results demonstrated that PTO and DDPT from D. versipellis have potential to be employed in adjuvant therapy for treating human prostate and breast tumors. Further studies of the 
specific mechanisms of these compounds on human malignant tumors are currently underway.

\section{Acknowledgements}

The authors wish to thank the National Key Program for Basic Research (No. 2010CB126105) and the National Basic Research Preliminary Program of China (Grant 2010CB134504) and the National Natural Science Foundation of China (No. 20872021) for the financial support.

\section{Authors' contributions}

$\mathrm{XQX}, \mathrm{XHG}$ performed the experiments, analyzed the data and wrote the paper. KY performed the experiments, LHJ, DH planned and analyzed the data and BAS, SY planned the experiments, wrote the paper and give final approval of the version to be published. All authors contributed to this study, read and approved the final manuscript.

\section{Competing interests}

The authors declare that they have no competing interests.

Received: 22 February 2011 Accepted: 15 June 2011

Published: 15 June 2011

\section{References}

1. Scheck AC, Perry K, Hank NC, Clark WD: Anticancer activity of extracts derived from the mature roots of Scutellaria baicalensis on human malignant brain tumor cells. BMC Complement Altern Med 2006, 6:27.

2. Mousseau M, Schaerer R, Pasquier B, Chauvin C, Nissou MF, Chaffanet M, Plantaz D, Benabid A: A study of the expression of four chemoresistancerelated genes in human primary and metastatic brain tumours. Eur $J$ Cancer 1993, 29:753-759.

3. Huncharek M, Mcgarry R, Kupelnick B: Impact of intravesical chemotherapy on recurrence rate of recurrent superficial transitional cell carcinoma of the bladder: results of a meta-analysis. Anticancer Res 2001, $21: 765-769$

4. Shibata MA, Hasegawa R, Kurata Y, Yamada M, Tamano S, Fukushima S: Bladder epithelial hyperplasia in F344 rats after intravesical instillation of the antitumor chemotherapeutic agents Adriamycin ${ }^{\circledR}$ and mitomycin $C$. Cancer Lett 1990, 49:41-49.

5. Walker MC, Masters JR, Parris CN, Hepburn PJ, English PJ: Intravesical chemotherapy: in vitro studies on the relationship between dose and cytotoxicity. Urol Res 1986, 14:137-140.

6. Panichakul T, Intachote P, Wongkajorsilp A, Sripa B, Sirisinha S: Triptolide sensitizes resistant cholangiocarcinoma cells to TRAIL-induced apoptosis. Anticancer Res 2006, 26:259-265.

7. Bemis DL, Capodice JL, Anastasiadis AG, Katz AE, Buttyan R: Zyflamend ${ }^{\oplus}$, a unique herbal preparation with nonselective COX inhibitory activity, induces apoptosis of prostate cancer cells that lack COX-2 expression. Nutr Cancer 2005, 52:202-212.

8. Wang XJ, Wei YQ, Yuan SL, Liu GJ, Lu YR, Zhang J, Wang WD: Potential anticancer activity of tanshinone IIA against human breast cancer. Int $J$ Cancer 2005, 116:799-807.

9. Wang GF, Guo YW, Feng B, Li L, Huang CG, Jiao BH: Tanghinigenin from seeds of Cerbera manghas $L$. induces apoptosis in human promyelocytic leukemia HL-60 cells. Environ Toxicol Phar 2010, 30:31-36.

10. Chen Z, Liu YM, Yang S, Song BA, Xu GF, Bhadury PS, Jin LH, Hu DY, Liu F, Xue W, Zhou X: Studies on the chemical constituents and anticancer activity of Saxifraga stolonifera (L) Meeb. Bioorg Med Chem 2008, 16:1337-1344.

11. Damayanthi Y, Lown JW: Podophyllotoxins: current status and recent developments. Curr Med Chem 1998, 5:205-252.

12. Stähblin H: Activity of a new glycosidic lignan derivative (VP 16-213) related to podophyllotoxin in experimental tumors. Eur J Cancer 1973, 9:215-221.

13. Stähblin H: 4'-Demethyl-epipodophyllotoxin thenylidene glucoside (VM 26), a podophyllum compound with a new mechanism of action. Eur J Cancer 1970, 6:303-306.

14. VanVliet DS, Tachibana Y, Bastow KF, Huang ES, Lee KH: Antitumor agents. 207. ${ }^{1}$ Design, synthesis, and biological testing of $4 \beta$-anilino-2-fluoro-4'- demethylpodophyll- otoxin analogues as cytotoxic and antiviral agents. J Med Chem 2001, 44:1422-1428.

15. Castro MA, del Corral JMM, Gordaliza M, García PA, Gómez-Zurita MA, García-Grávalos MD, de la Iglesia-Vicente J, Gajate C, An F, Mollinedo F, Feliciano AS: Synthesis and biological evaluation of new selective cytotoxic cyclolignans derived from podophyllotoxin. J Med Chem 2004, 47:1214-1222.

16. Jiang RW, Zhou JR, Hon PM, Li SL, Zhou Y, Li LL, Ye WC, Xu HX, Shaw PC, But PPH: Lignans from Dysosma versipellis with inhibitory effects on prostate cancer cell lines. J Nat Prod 2007, 70:283-286.

17. Yu PZ, Wang $L P$, Chen $Z N$ : A new podophyllotoxin-type lignan from Dysosma versipellis var. tomentosa. J Nat Prod 1991, 54:1422-1424.

18. Shang MY, Xu LS, Li P, Xu GJ, Wang YX, Cai SQ: Study on pharmacodynamics of Chinese herbal drug Guijiu and its lignan. Chin Tradit Herb Drugs 2002, 33:722-724.

19. Wu ZH, Zhao YM, Zhong SG, Li CT, Sun YW, Li WH: Proliferation inhibiting and apoptosis inducing on $\mathrm{HL}-60$ by podophyllotoxone. Chin J Pract Chin Modern Med 2002, 2:568-569.

20. Yin ML, Chen ZL, Gu ZS, Xie YX: Separation and identification of chemical constituents of Dysosma majorense. Acta Botan Sin 1990, 32:45-48.

21. You YJ, Kim Y, Nam NH, Ahn BZ: Antitumor activity of unsaturated fatty acid esters of 4'-demethyldeoxypodophyllotoxin. Bioorg Med Chem Lett 2003, 13:2629-2632.

22. Xie XY, Gong JY, Wang LY, Zhang ZJ, Yu CY: Chemical constituents of the root of Rosa davurica pall. Lishizhen Med Mater Med Res 2009, 20:366-367.

23. Liao MC, Wang YW, Tu ZB, Xiao PG: Study on constituents of Dysosma tsayuensis Ying. J Wuhan Bot Res 2002, 20:71-74.

24. Hu XL, Zhu H, Liu CR, Tu PF: Study on the chemical constituents of the flowers of Impatiens balsamina L. Chin Tradit Patent Med 2003, 25:833-834.

25. Shang MY, Cai SQ, Li P: Study on constituents of Dysosma furfuracea Bao. Chin Tradit Herb Drugs 2000, 31:412-414.

26. AL-Abed Y, Sabri S, Zarga MA: Chemical constituents of the flora of Jordan, partv-b. Three new arylnaphthalene lignan glucosides from Haplophyllum buxbaumii. J Nat Prod 1990, 53:1152-1161.

27. Zhou YJ, Xu SX, Sun QS, Zhang PC, Wu LJ: A study on the chemical constituents of Quercus engleriana Seem. J Shenyang Pharm Univ 2000, 17:263-266.

28. Broomhead AJ, Dewick PM: Tumour-inhibitory aryltetralin lignans in Podophyllum versipelle, Diphylleia cymosa and Diphylleia grayi. Phytochemistry 1990, 29:3831-3837.

29. Zhang HJ, Chen YG, Huang R: Study on flavonoids from Hedyotis diffusa Willd. J Chin Med Mater 2005, 28:285-287.

30. Zhu PF, Wang YS, Zhao JF, Zhang HB: Study on lignans of Dysosma versipellis. J Yunnan Univ 2006, 28:521-525.

31. Yu DQ, Yang JS, Xie JY: Analytical Chemistry Handbook. Bei Jing: Chemical Industry Press; 1989.

32. An Q, Yang CJ, Song Y, Yu K, Xiong ZL, Li FM: Studies on the chemical constituents of the fruit of Acanthopanax sessiliflorus (Rupr. et Maxim.) Seem. Nat Prod Res Dev 2008, 20:765-769.

33. Ma ZW, He GF: Studies on chemical constituents of Emmenopterys henryi Oliv. Native to China. J Integr Plant Biol 1989, 31:620-625.

34. Ma C, Yang JS, Luo SR: Study on lignans from Diphylleia sinensis. Acta Pharmacol Sin 1993, 28:690-694.

35. Jackson DE, Dewick PM: Aryltetralin lignans from Podophyllum hexandrum and Podophyllum peltatum. Phytochemistry 1984, 23:1147-1152.

36. Shen XJ, Ge RL, Wang JH: Chemical constituents from Choerospondias axillaris (Roxb.) Burtt. et Hill. J Henan Univ (Med Sci) 2009, 28:196-199.

37. Shaari K, Waterman PG: Podophyllotoxin-type lignans as major constituents of the stems and leaves of casearia clarkei. J Nat Prod 1994, 57:720-724.

38. Zhou L, Wang N, Miao F, Zhao HS, Tian P: Chemical consitituents of gentiana apiata N. E. Br. Chin J Org Chem 2004, 24:1249-1252.

39. Ronald H, Blum MD, Stephen K, Carter MD: Adriamycin, a new anticancer drug with significant clinical activity. Ann Intern Med 1974, 80:249-259.

40. Nakaike S, Yamagishi T, Samata K, Nishida K, Inazuki K, Ichihara T, Migita Y, Otomo $S$, Aihara $H$, Tsukagoshi $S$ : In vivo activity on murine tumors of a novel antitumor compound, $N$ - $\beta$-dimethylaminoethyl 9-carboxy-5hydroxy-10-methoxybenzo[a] phenazine-6-carboxamide sodium salt (NC190). Cancer Chemoth Pharm 1989, 23:135-139. 
41. Xie YM, Deng Y, Dai XY, Liu J, Ouyang L, Wei YQ, Zhao YL: Synthesis and Biological Evaluation of Novel Acenaphthene Derivatives as Potential Antitumor Agents. Molecules 2011, 16:2519-2526.

42. Wang S, Xie Y: China Species Red List. Beijing: Higher Education Press; 2004.

43. Guan BC, Qiu YX, Fu CX: Isolation and characterization of microsatellite markers in Dysosma versipellis (Berberidaceae), a rare endemic from China. Conserv Genet 2008, 9:783-785.

doi:10.1186/1747-1028-6-14

Cite this article as: Xu et al.: Antiproliferation and cell apoptosis inducing bioactivities of constituents from Dysosma versipellis in PC3 and Bcap-37 cell lines. Cell Division 2011 6:14.

Submit your next manuscript to BioMed Central and take full advantage of:

- Convenient online submission

- Thorough peer review

- No space constraints or color figure charges

- Immediate publication on acceptance

- Inclusion in PubMed, CAS, Scopus and Google Scholar

- Research which is freely available for redistribution

Submit your manuscript at www.biomedcentral.com/submit 